\title{
Hydroxamate siderophores: Natural occurrence, chemical synthesis, iron binding affinity and use as Trojan horses against pathogens
}

\author{
Danah Al Shaer ${ }^{\mathrm{a}, \mathrm{b}}$, Othman Al Musaimi ${ }^{\mathrm{a}, \mathrm{b}}$, Beatriz G. de la Torre ${ }^{\mathrm{a}, * *}$, Fernando Albericio ${ }^{\text {b,cd,* }}$ \\ ${ }^{a}$ KRISP, School of Laboratory of Medicine and Medical Science, College of Health Sciences, University of KwaZulu-Natal, Durban, 4001, South Africa \\ ${ }^{\mathrm{b}}$ School of Chemistry and Physics, University of KwaZulu-Natal, Durban, 4001, South Africa \\ c Institute for Advanced Chemistry of Catalonia (IQAC-CSIC), Jordi Girona 18-26, 08034, Barcelona, Spain \\ ${ }^{\mathrm{d}}$ CIBER-BBN, Networking Centre on Bioengineering, Biomaterials and Nanomedicine and Department of Organic Chemistry, University of Barcelona, 08028, Barcelona, Spain
}

\section{A R T ICLE INFO}

Article history:

Received 1 August 2020

Received in revised form 23 August 2020

Accepted 24 August 2020

Available online $\mathrm{xxx}$

\section{Keywords}

Siderophore

Hydroxamate

Trojan horse

Siderophore-drug conjugate

Fe (III) binding affinity

Sideromycins

\begin{abstract}
A B S T R A C T
Hydroxamic acids are an important class of molecules, in particular because of their metal-chelating ability. Microorganisms, including pathogenic bacteria, use hydroxamate-based entities (siderophores), among others, to acquire Fe (III). The "Trojan horse" strategy exploits the need of bacteria for this metal by using Fe (III) active transporters to carry antibacterial or bactericidal moieties into the bacterial cell. Many natural Trojan horses (sideromycins) are derived from hydroxamic acids, thereby reflecting their potency. Various artificial sideromycins and their antibacterial activities have been reported. This review discusses the structural aspects of the hydroxamate-siderophores isolated in the last two decades, the chemical synthesis of their building blocks, their binding affinity towards Fe (III), and their application as Trojan horses (weaknesses and strengths).
\end{abstract}

(C) 2020

\section{Introduction}

Iron is an essential nutrient for most living organisms [1]. Although accounting for about $35 \%$ of Earth's mass [2], its bioavailability to microorganisms is limited. This is attributed to the fact that under anaerobic conditions, iron is present as Fe (III), which in aqueous media is either precipitated out (trapped) as insoluble hydroxides (Ksp $=10^{-18} \mathrm{M}$ ) or is bound to host proteins such as transferrin, ferritin and lactoferrin leaving the free Fe (III) at concentrations as low as $1 \times 10^{-24} \mathrm{M}[1,3]$.

To acquire iron in iron-deficient environments, microorganisms (such as bacteria and fungi) produce "Siderophores" [1,4], the Greek term meaning iron carriers. Siderophores have specific and high affinity towards iron, thus allowing microorganisms to scavenge this coveted nutrient from their environment and ensure their survival.

Fe (III) forms octahedral complexes with six electron-donating atoms symmetrically spatially distributed around the central iron. Maximum binding affinity is achieved when all six atoms interacting with

\footnotetext{
* Corresponding author. School of Chemistry and Physics, University of KwaZulu-Natal, Durban, 4001, South Africa.

** Corresponding author.

E-mail address: albericio@ukzn.ac.za (F. Albericio)
}

iron are present in the same molecule, thus emphasizing the "chelate effect" in the multiple denticity. Natural siderophores are mostly hexadentates, in which the binding units vary between catecholates, $\alpha$-hydroxy carboxylates, hydroxamates and a mixture of these functional groups [5] (Fig. 1).

The microbial iron uptake cycle starts with the production and secretion of "endogenous" siderophores (those produced by the cell itself) into the surroundings. These siderophores solubilize Fe(III) from its hydroxide or capture it from host proteins [6]. Ferrisiderophores (siderophore-Fe(III) complexes) are usually more than $500 \mathrm{Da}$, which means that they require certain transport systems to transfer them into the cell. Specific membrane (outer membrane in gram-negative bacteria) protein receptors recognize the complex via key features [6,7]. Recognition triggers the transport system and subsequent uptake occurs. Some outer membrane protein receptors are binding unit-specific and can recognize a wide spectrum of siderophores with same type of chelating units, such as FhuA (ferric hydroxamate outer membrane receptor) and FecA (ferric citrate). This capacity allows some species to use the siderophores produced by other organisms (xenosiderophores) [8]. Other receptors are specific for only a given siderophore, such as FptA (ferric pyochelin transport) and FpvA (ferric pyoverdin) [9].

Although outer membrane receptors for ferrisiderophore mediate the nourishment (feeding) of the cell, they can also poison it. Some microorganisms hybridize the siderophore with a bactericidal moiety 

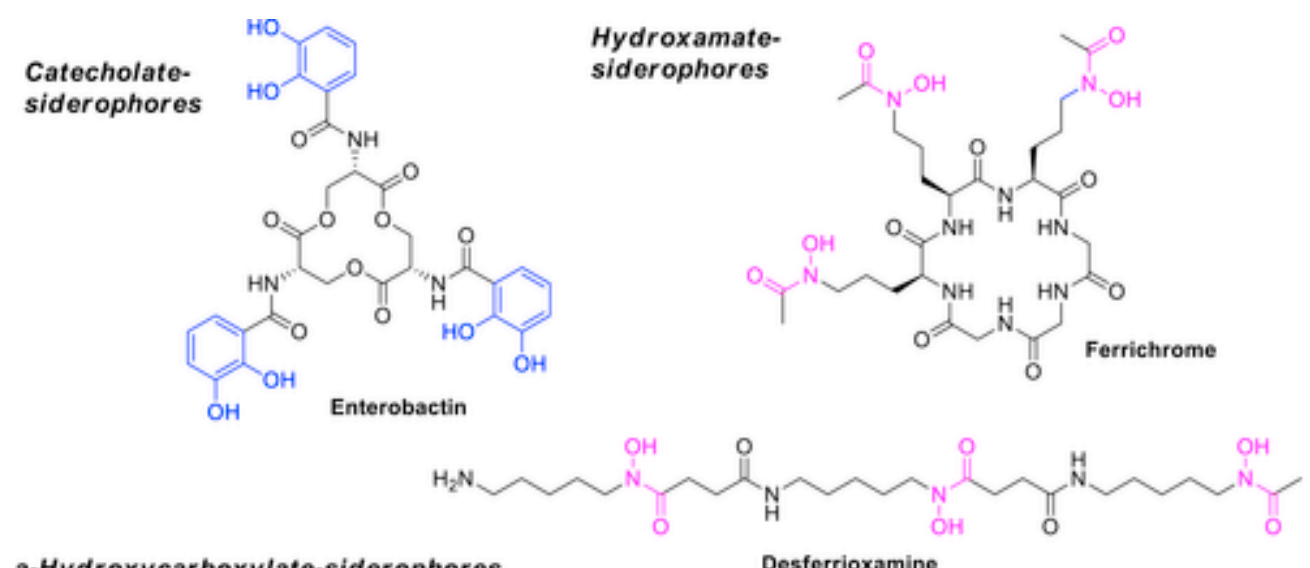

a-Hydroxycarboxylate-siderophores

Desferrioxamine<smiles>O=C(O)CC(O)(CC(=O)NCCCC(NC(=O)CC(O)(CC(=O)O)C(=O)O)C(=O)O)C(=O)O</smiles>

Staphyloferrin A

Mixed siderophores<smiles>CC(NC(=O)C(C)NC(=O)C(C)C(=O)NC(C)C(=O)NC(C(=O)O)C(=O)NC1CCCN(O)C1=O)C(=O)O</smiles><smiles>[R]C(=O)NCCCC[C@H](NC(=O)C1N=C(c2c([R])cccc2O)OC1[R])C(=O)OC([R])C([R])C(=O)NC1CCCCN(O)C1=O</smiles>

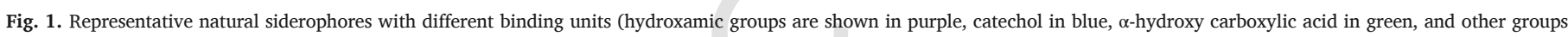
in maroon). (For interpretation of the references to colour in this figure legend, the reader is referred to the Web version of this article.)

(sideromycin $=$ sideophore + antibiotic) to attack other species and kill them. This microbial strategy (Trojan horse) has inspired the research community to develop a new approach to increase the permeability of the drug into the multi-drug resistant cell [10-12]. In this regard, increasing bacterial resistance to almost all known antibiotics has come about from the overuse of antibiotics for the treatment of bacterial infections $[13,14]$. The discovery of only a handful of novel antibiotics over the last few decades has made it necessary to devise innovative strategies to combat pathogenic bacteria [15], the Trojan horse strategy emerging as a promising approach.

Among the five known families of natural sideromycins, three-albomycins, ferrimycins and salmycins-use the hydroxamate binding moiety (the other two families are salmochelim and microcin). Albomycins (3, Fig. 2) are the most widely known natural sideromycins and they have a proven efficiency against many organisms with the FhuA receptor in their outer membrane (see section 2.4.1.1). This activity emphasises the role of this family of chelators in overcoming the permeability barriers of the microbial cell wall [16].

In this review we discuss hydroxamate siderophores in terms of their natural occurrence, chemical synthesis, binding affinity towards Fe(III) and potency as antimicrobial drug conjugates.

\section{Hydroxamate-based siderophores}

Hydroxamic acids have the general formula $\mathrm{RC}(\mathrm{O}) \mathrm{N}(\mathrm{OH}) \mathrm{R}$. They can be defined as $N$-hydroxy amides. This structure gives the proton of the hydroxyl some acidic properties depending on the solvent, with pKa values of about 9 [17]. When deprotonated, hydroxamate ion can strongly bind to various positively charged metal ions (Fig. 2). In a wide spectrum of natural siderophores, the chelating unit of hydroxamic acid is found either within the backbone or as pendants (Fig. 2).

\subsection{Natural occurrence of hydroxamate siderophores}

Hydroxamate siderophores are produced mainly by fungi and some strains of bacteria. The first known families were ferrichrome (1, Fig. 2), which was isolated from smut fungus Ustilago sphaerogana [18], and coprogen (5) [19], both isolated and reported in 1952. The structure of ferrichrome was characterized later in 1960 [20]. Another hydroxamate siderophore is desferrioxamine B (DFO B,6), the most famous member of the ferrioxamine family. Nobel laureate Vladimir Prelog and co-workers isolated DFO B from Streptomyces pilosus and first reported it in 1960 [21]. Ciba-Geigy (now Novartis) introduced DFO B to the market as a strong metal chelator and this compound was later approved by US Food and Drug Administration (FDA) in 1968 as "Desferal" for the treatment of iron poisoning (iron overloading) [22].

Albomycins are hydroxamate sideromycins. They were reported previously as grisein [23] and were first isolated in 1947, but their structures were not fully characterized till 1982 [24] (see section 2.4.1.1).

Many other hydroxamate siderophores have since been isolated and reported [25]. In the last two decades (2000-to date), more than 135 new members have been added to the family (entries 10-61, Table 1 ), many extracted mainly from bacterial species collected from the Atlantic Ocean [26]. Most hydroxamate siderophores are hydrophilic. In contrast, most marine siderophores are amphiphilic, having both hydrophilic and hydrophobic parts in their structure, the latter enabling the siderophore to form micelles when complexed to Fe(III), thereby in- 
Siderophores with hydroxamate pendants:

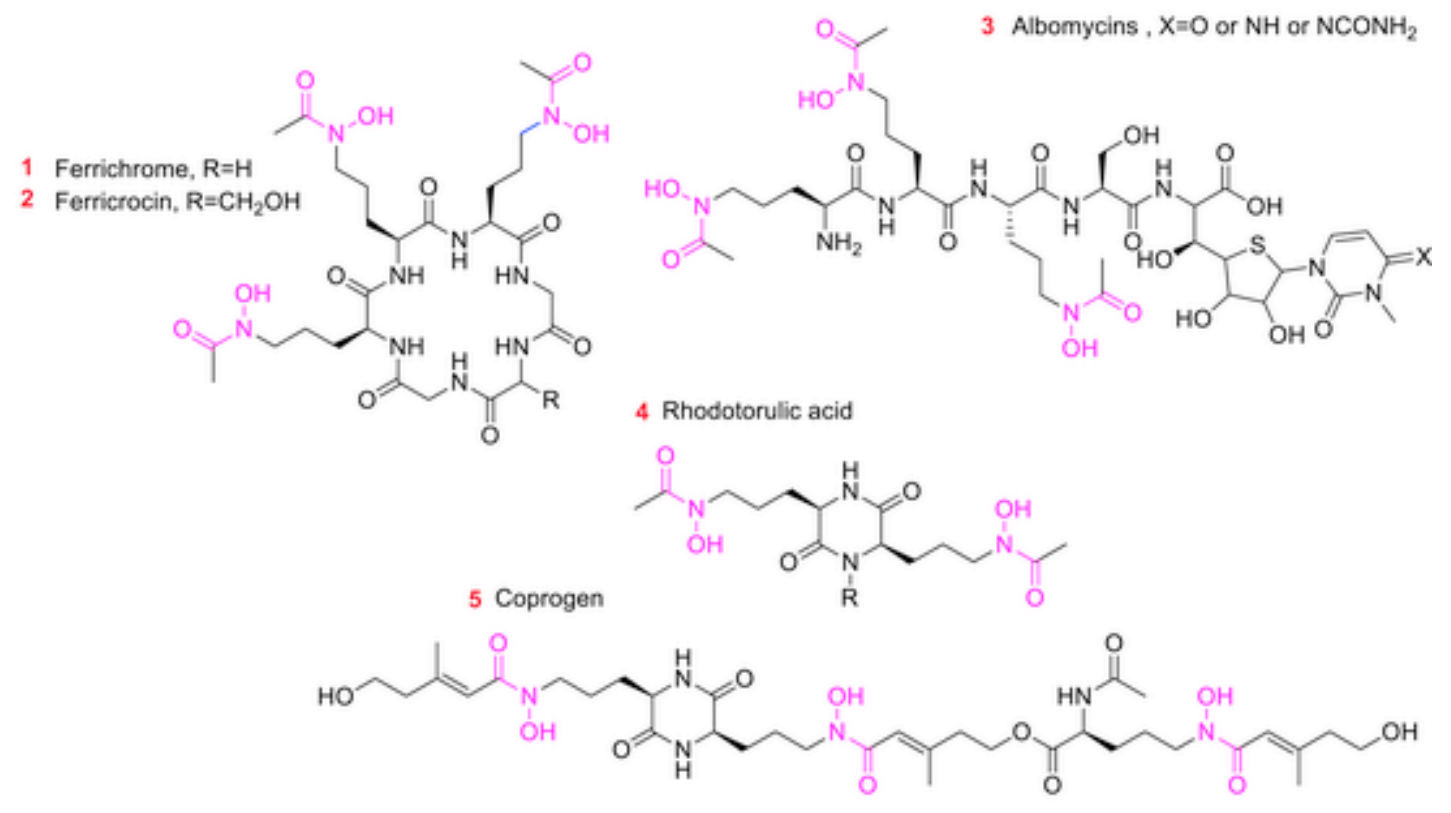

Siderophores with backbone hydroxamate:<smiles>[R]NCCCCCN(O)C(=O)CCC(=O)NCCCCCN(O)C(=O)CCC(=O)NCCCCCN(O)C(C)=O</smiles>

\section{Representative Hydroxamate-Fe(III) complex}<smiles>[R]C(=O)NO[C@@]1(C)ON([R])O[C@]1(C)OC([R])=O</smiles>

Fig. 2. Representative hydroxamate-derived siderophores.

creasing the availability of the complex to the cell in the seawater environment [27]. Ferrioxamine $\mathrm{E}$ and $\mathrm{G}$ are among the most soluble marine siderophores [26]. Table 1 shows most of the hydroxamate siderophores isolated in the period 2000-2020, their structures and the species that produce them (see Table 2).

From a structural point of view, all the siderophores in Table 1 contain the hydroxamate chelating unit, either alone as in entries 10-29 and 34-38, or mixed with other binding units as in entries 30-33 and 39-61. The hydroxamate parts are derived from Orn, Lys, or N-hydroxydiaminoalkane [17]. In Orn-derived hydroxamates, the $\delta-\mathrm{N}$ of the Orn is hydroxylated and acylated. The acylation moieties vary between formyl, as in $13,17,23-26,30,31$, and 33, acetyl as in 10-12 and $\mathbf{1 4}-\mathbf{1 5}$, malonyl as in 16, or anhydro-mevalonyl as in 20-22 and 28, 3-hydroxy-butanoyl as in 27, 3-methyl-glutaconyl as in $\mathbf{2 9}$ (this acyl is an intermediate in leucine metabolism [84]), fatty acid as in 56-57, $\alpha-\mathrm{COOH}$ of the Orn itself forming a six membered cycle as in 23-26, or the $\alpha-\mathrm{COOH}$ of another amino acid within the backbone (Arg, Asn, or Ser) as in 17-19 and 24-26. Some siderophores show two or more different acylating moieties for the distinct hydroxamate groups within the same molecule as in 17-19 and 23-26. 
Table 1

Hydroxamate siderophores isolated and reported in 2000-2020.

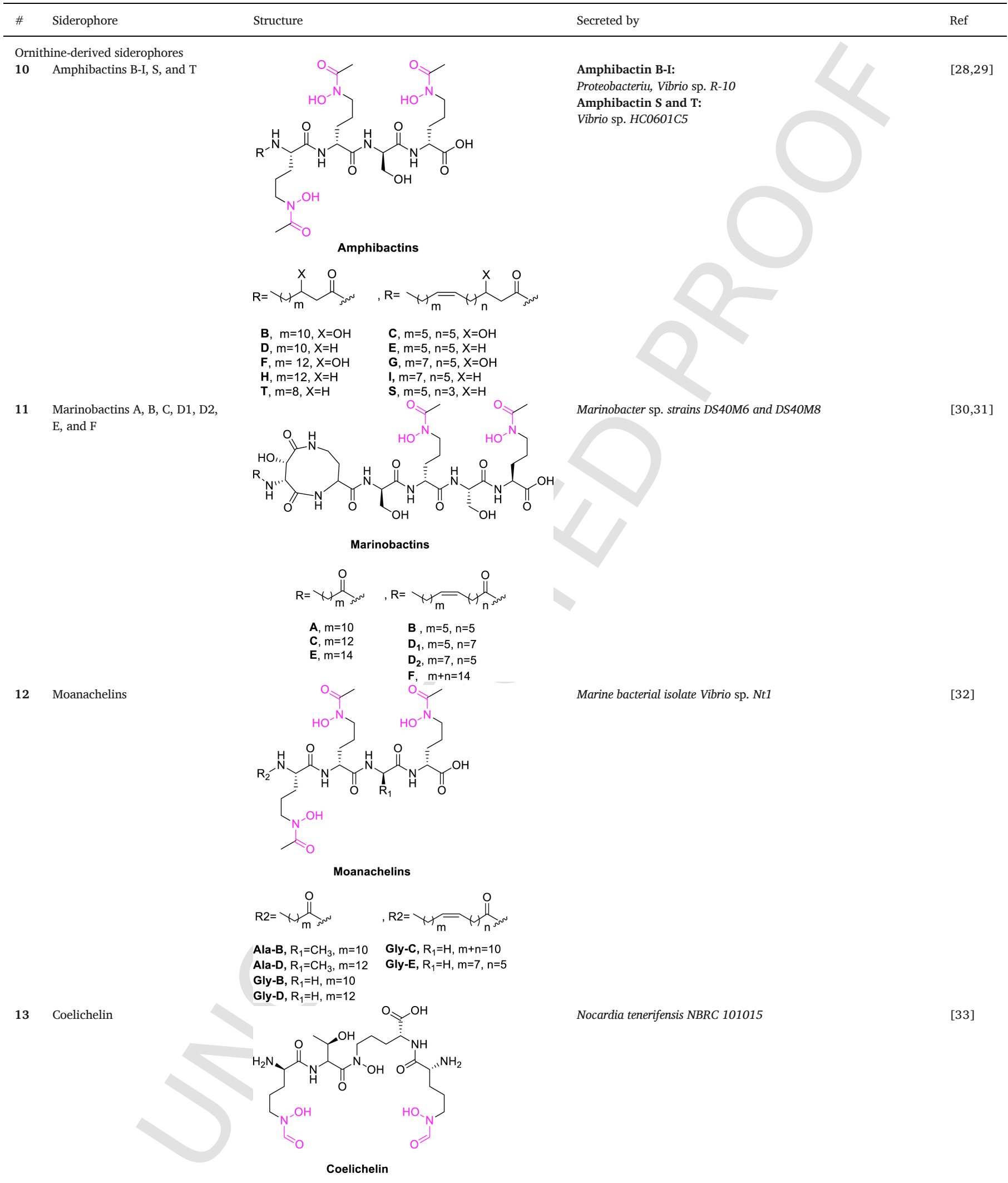




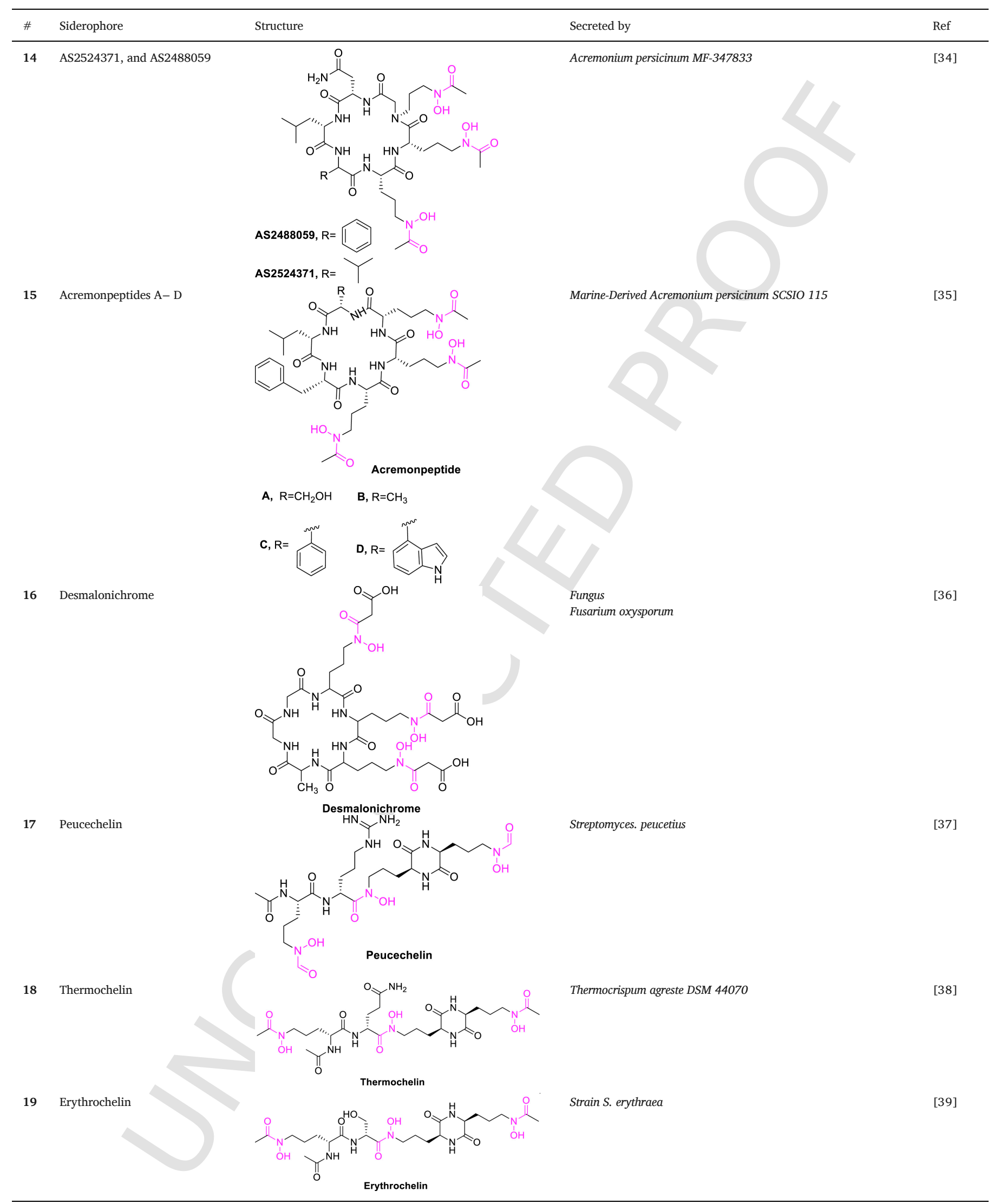




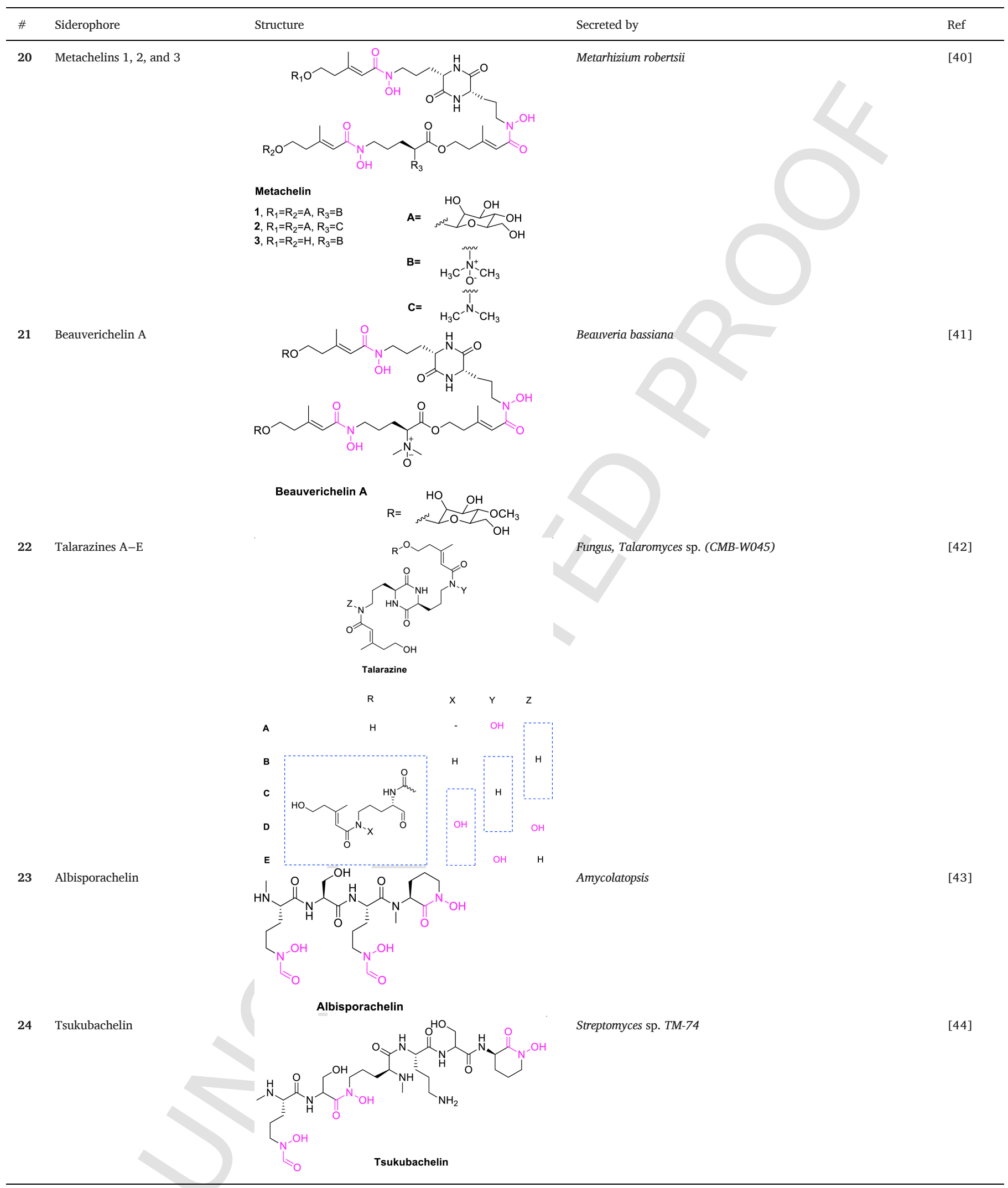




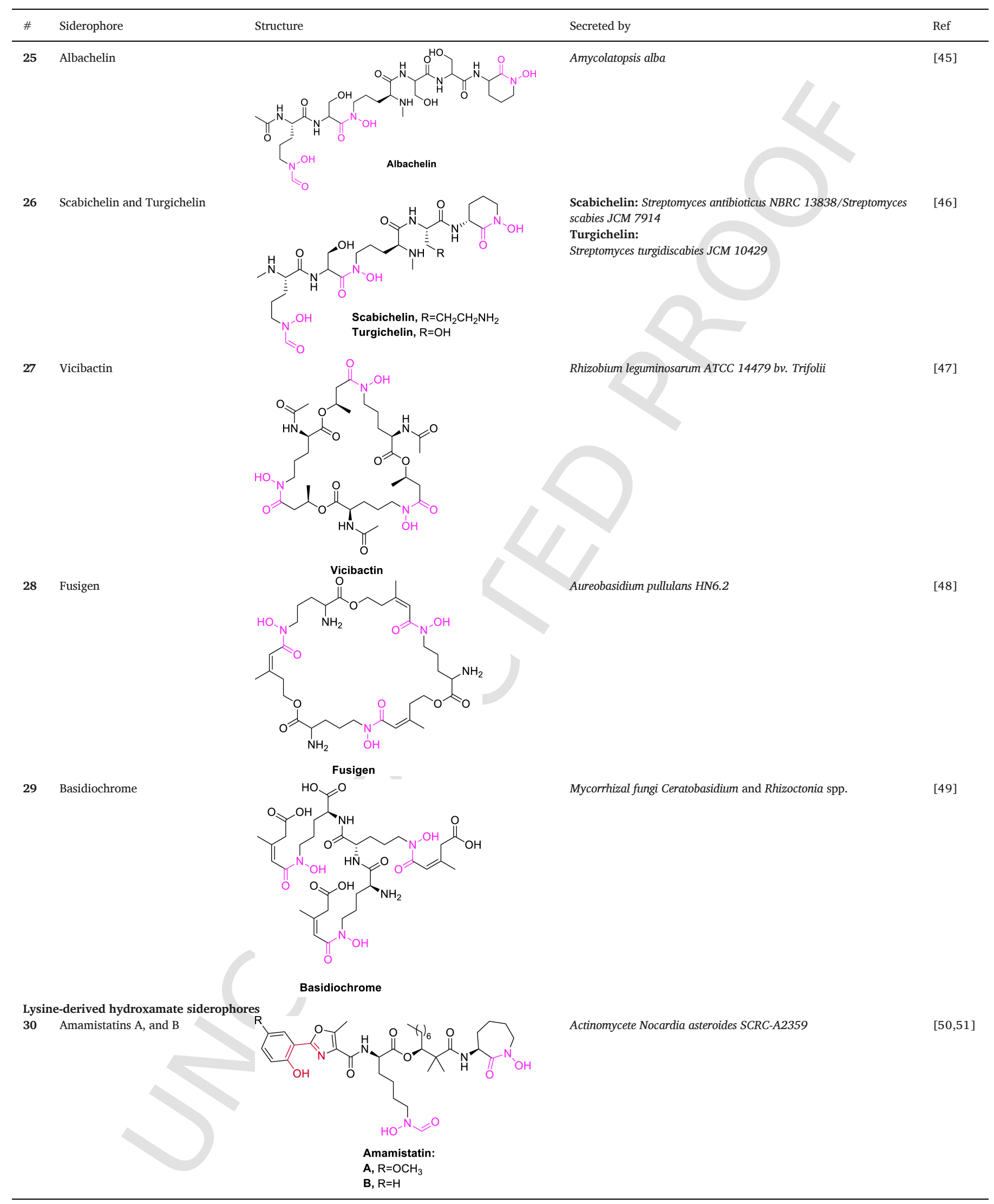




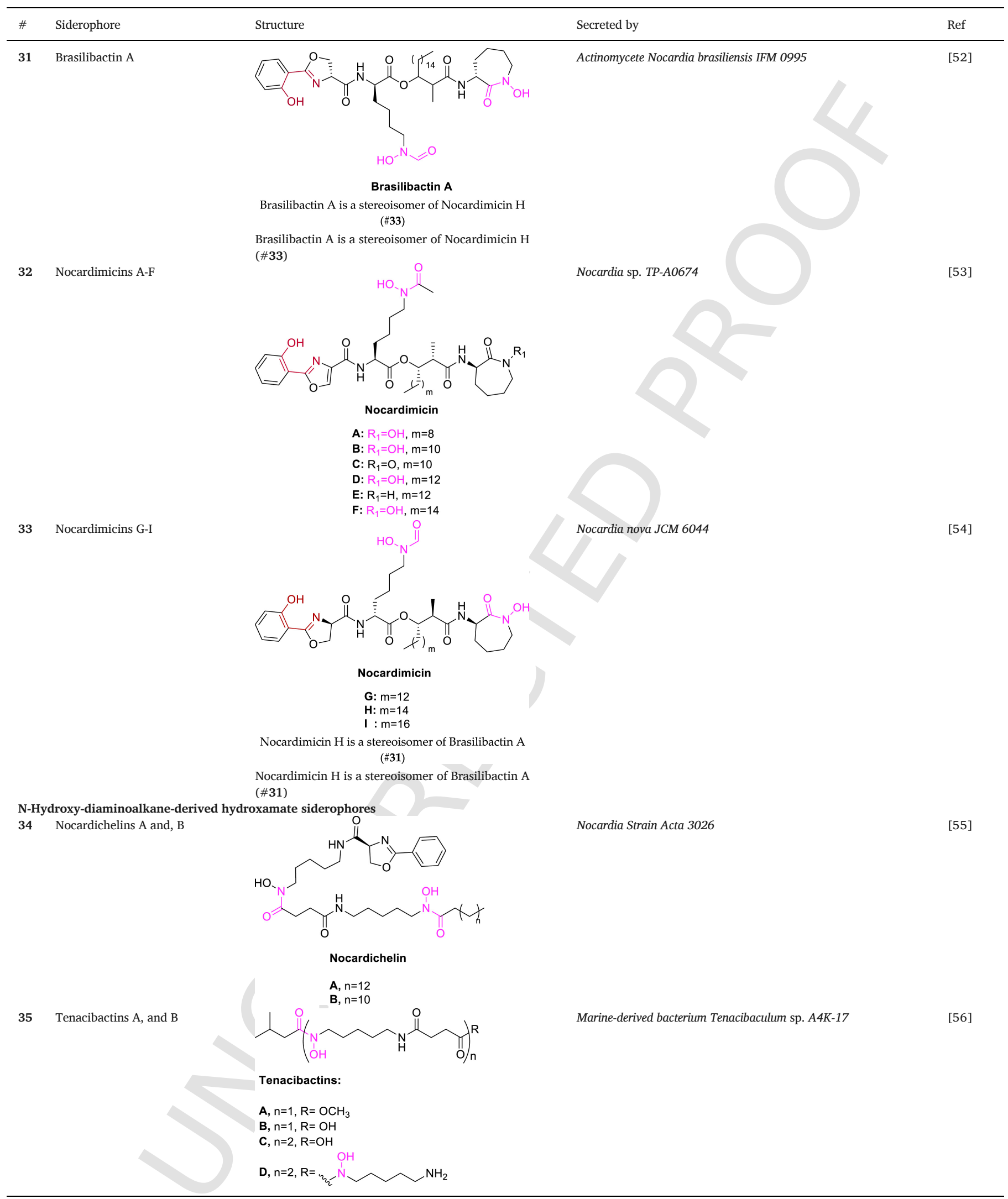




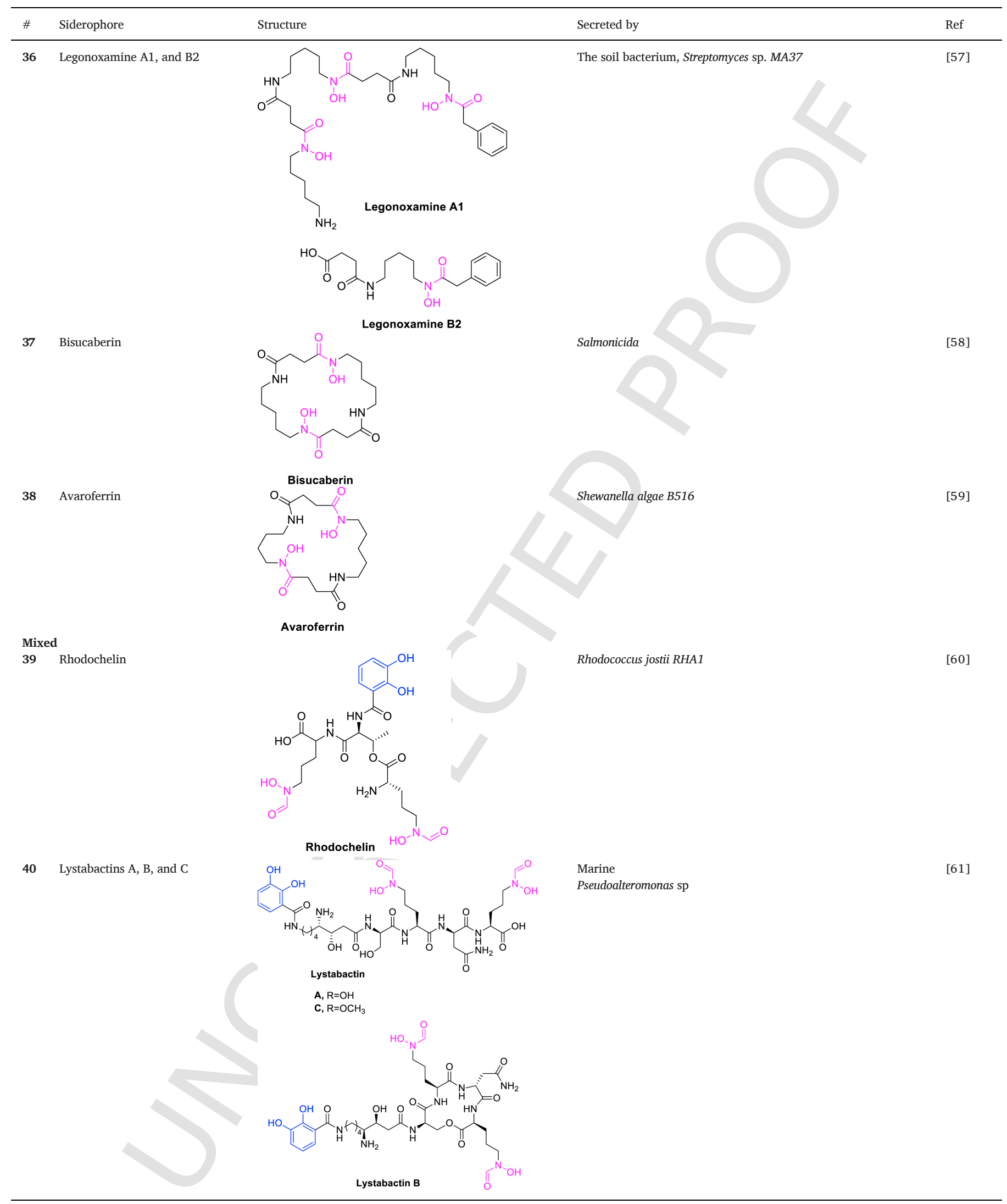




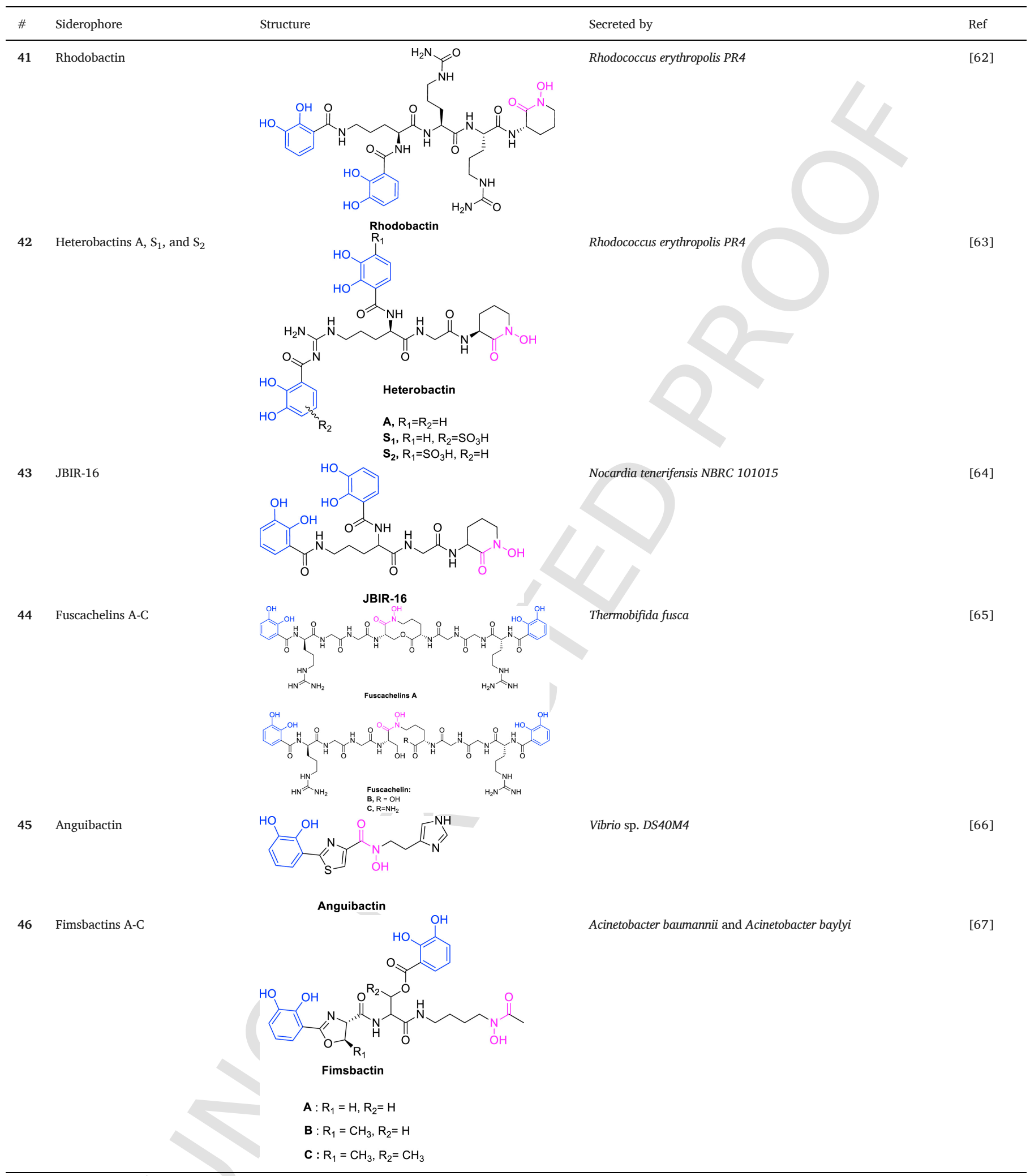




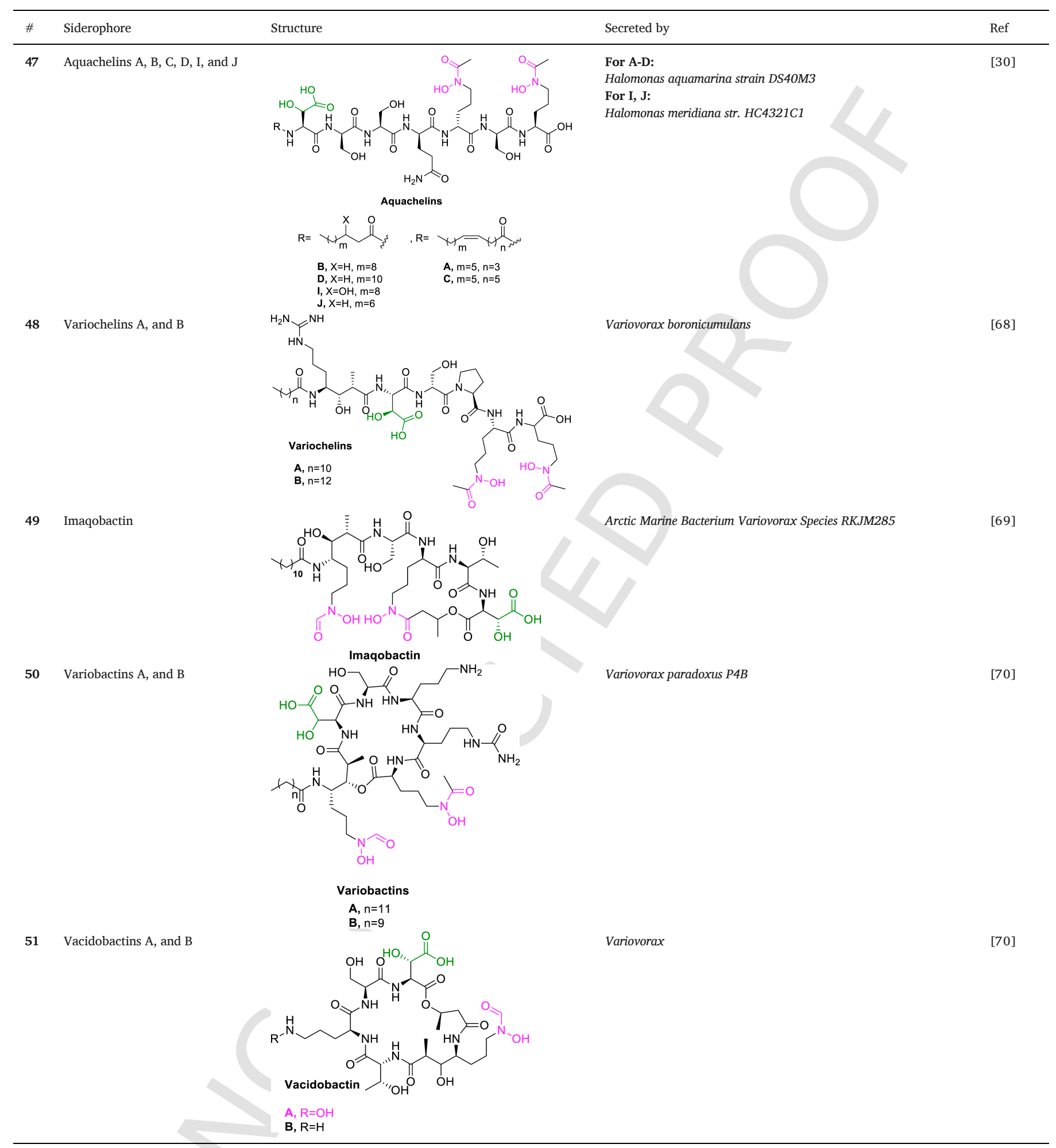


12

D. Al Sharer et al. / European Journal of Medicinal Chemistry xxx (xxx) 112791

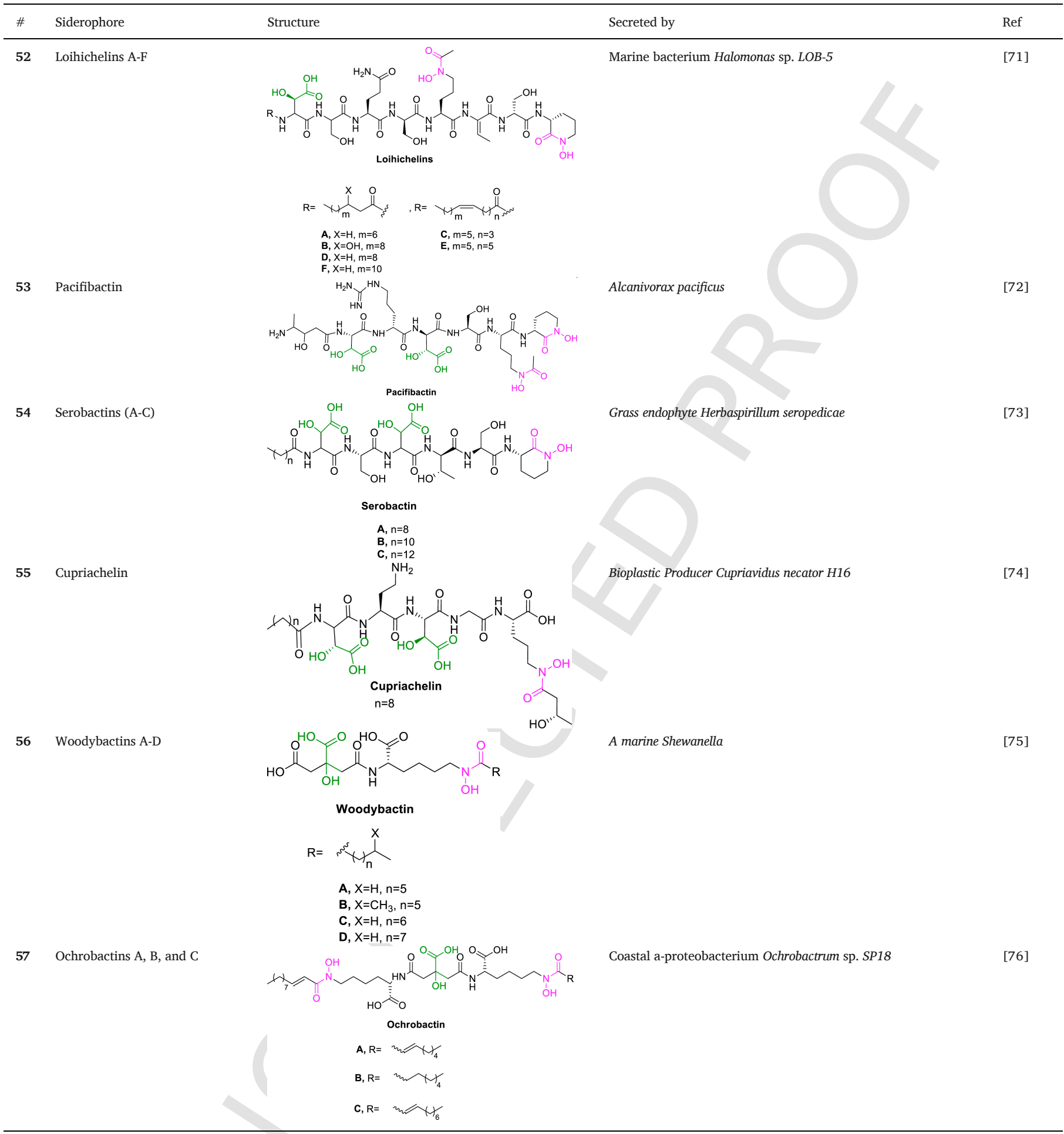




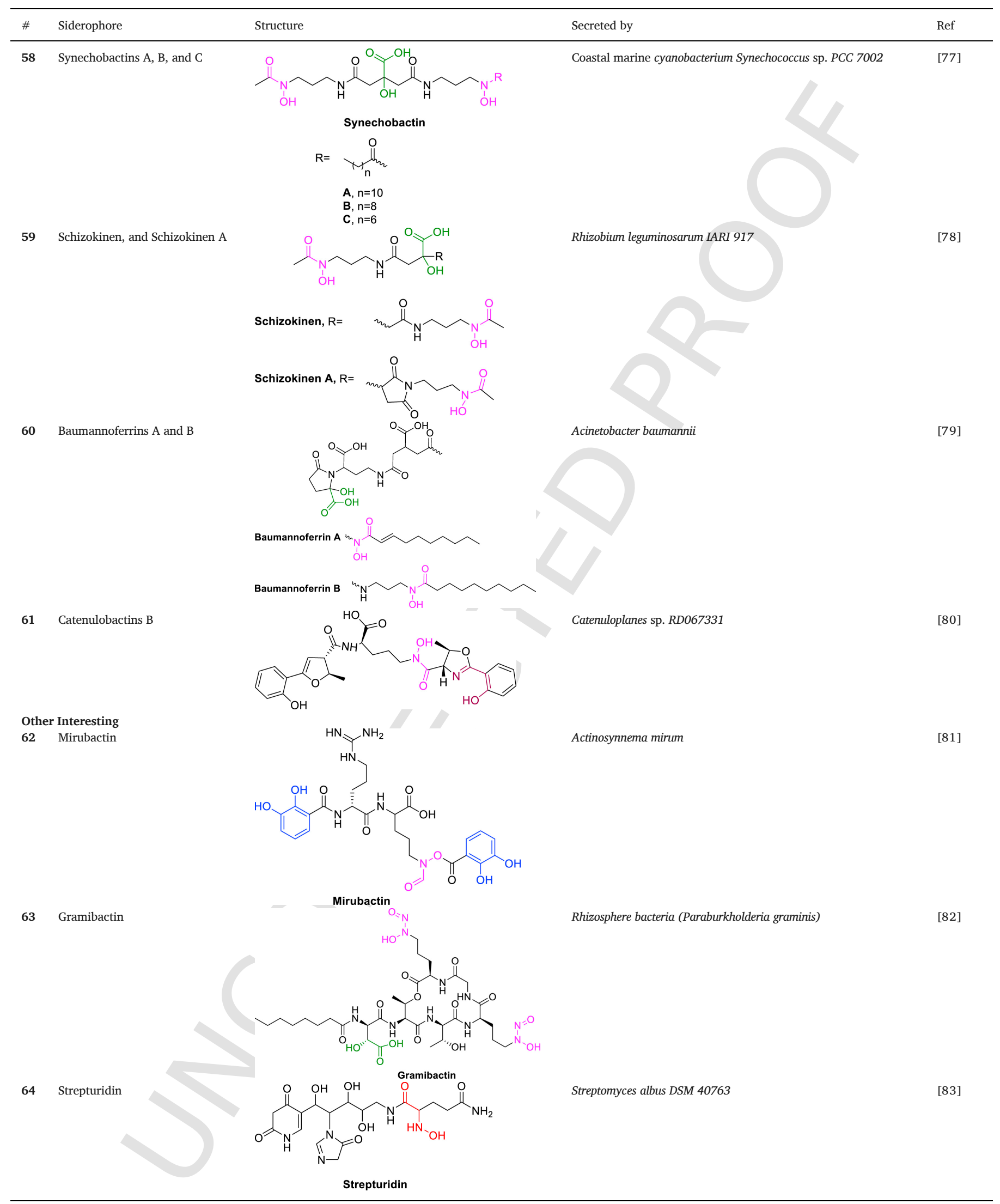


Also, $\varepsilon$-hydroxamate Lys residues are found in amamistatins (30), brasilibactin (31), nocardimicins (32 and 33), with the acylating moieties varying as in the Orn siderophores.

Other hydroxamate siderophores are derived from N-hydroxy-1,5-diaminopentane as in 34-38 and are usually acylated with a succinic moiety. N-hydroxy-1,5-diaminobutane is found in $\mathbf{3 8}$.

Many of these hydroxamate siderophores are peptides. They show a variety of structures. In agreement with the previously known representative siderophores, siderophores 10-13 are linear with hydroxamate appendages, as in albomycin (3) (although 11 has a cyclic part but the chelating unit is linear). Siderophores $\mathbf{1 4 - 1 6}$ are cyclic peptides (lactams) with exocyclic hydroxamate appendages as in ferrichrome $\mathbf{1 .}$

Entries 17-22 resemble coprogen (5), a tris hydroxamate siderophore with a cyclic di-Orn part with hydroxamate side chains. The denticity is extended to hexadentate through the acyl (peptidyl) part of the hydroxamate moieties to include an additional functionalized Orn as in 17-19, or other hydroxamate containing acyl as in 20-22.

The hydroxamate in the non-peptidyl siderophores are found only with the backbone (not as appendages) and the backbones are either linear as in 35-37 or cyclic (endo cyclic hydroxamate) as in 38-39.

\subsection{Chemical synthesis of hydroxamate residues in siderophores}

Several synthetic pathways can be used to prepare hydroxamic acids. In this regard, these acids can be synthesized from carboxylic acids [85], esters [86], aldehydes [87], alkyl halides [86], amines [88,89], and nitro compounds $[90,91]$. All reported methods can be briefly outlined as one of the five possible routes (either full or sub-route) shown in Scheme 1, which illustrates the most general ap- proaches for the synthesis of hydroxamic acids from alkyl amines, hydroxyl amine or simple amides.

\subsubsection{Synthesis of $\delta$-acyl- $\delta$-N-Hydroxy-Orn building block}

To prepare the $\delta$-acyl- $\delta$-N-hydroxy-ornithine building unit, most of the reported procedures involved the conversion of the alkylamine (in this case the Orn side chain) to N-hydroxyl alkylamine and then to $\mathrm{N}$-acyl-N-hydroxyl alkylamine (the red route in Scheme 1). The hydroxylation of the primary amine $\left(\delta-\mathrm{NH}_{2}\right)$ is the crucial step in the synthesis, and various approaches for this reaction have been reported in the literature. The syntheses start with Orn, with suitable protecting groups for the $\alpha-\mathrm{NH}_{2}$ and $\mathrm{COOH}$. Next, $\delta$-N is hydroxylated mostly with benzoyl peroxide in a biphasic mixture at $\mathrm{pH}=10.5[88,89,92]$ (Scheme 2). Although this is the most widely used protocol, it is hampered by low yield and requires critical purification due to the formation of the $\delta$-benzamide by-product. Another peroxide, dimethyl dioxirane (DMD) with acetone, was used for the oxidation of the amine to provide the nitrone (the N-oxide of the imine) and then the hydroxamic acid in two steps [87] (Scheme 3). In other cases, and following the same imine-nitrone approach, the hydroxylation step was done by reacting the $\delta-\mathrm{N}$ of Orn with benzaldehyde in basic medium, followed by the addition of an oxidizing agent (m-CPBA) and then a treatment with acid to obtain $\mathrm{N}-\mathrm{OH}$. The advantage of this functionalization is that it can be done either to the building block (Scheme 3 ) or to the Orn residue side chains after the peptide has been built [87].

Once the $\delta-\mathrm{NH}_{2}$ has been hydroxylated, the acylation step is carried out using strong amide formation strategies, such as acyl halides [89,92], acyl anhydrides [87] and HATU [88], due to lower nucleophilicity of the hydroxylated amine compared to the free amine.

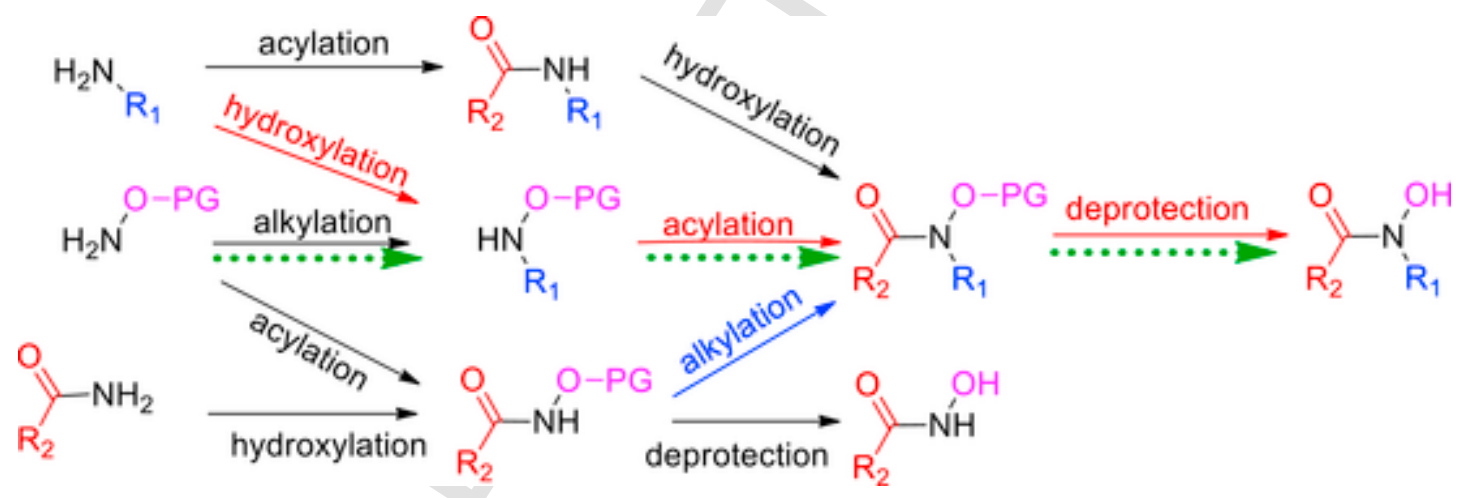

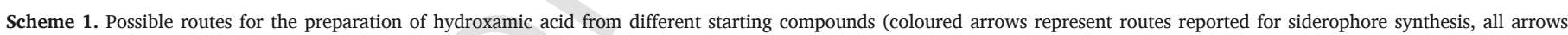
(black and coloured represent reported routes for hydroxamic acid preparation in general).

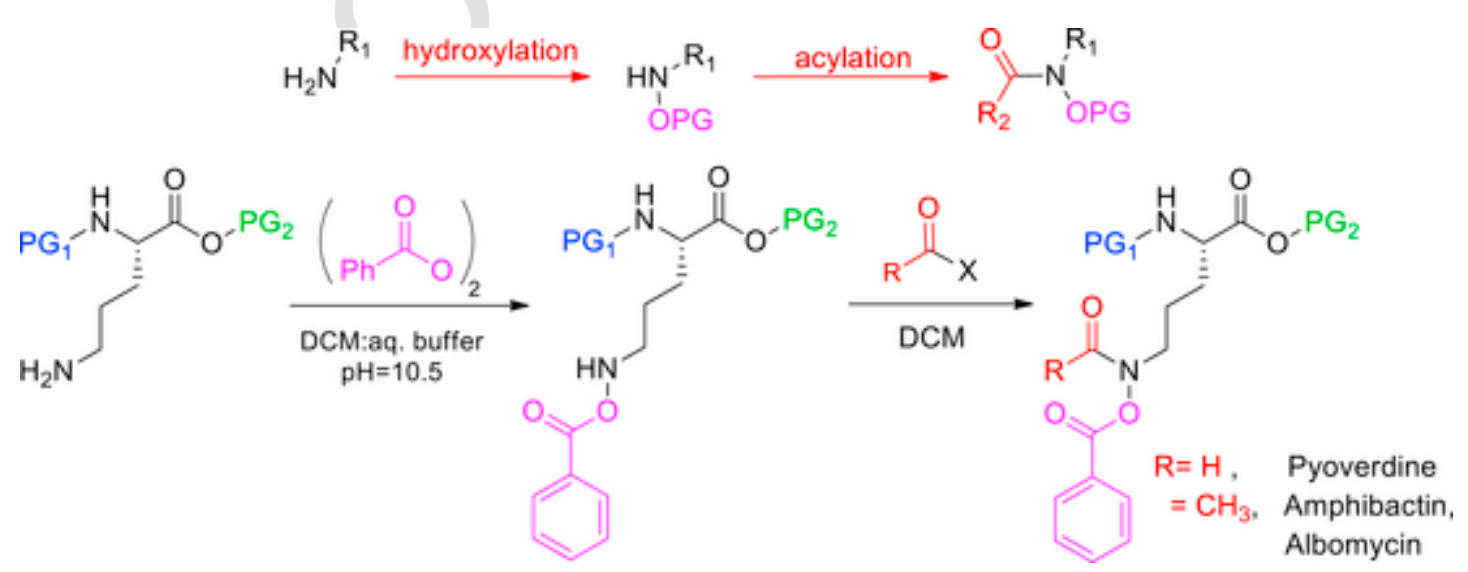

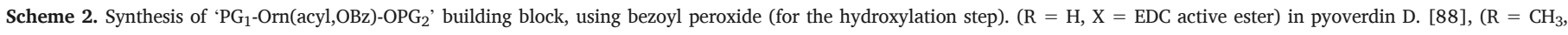
$\mathrm{X}=\mathrm{Cl}$ ) in amphibactin-T [92] and albomycin [89]. 


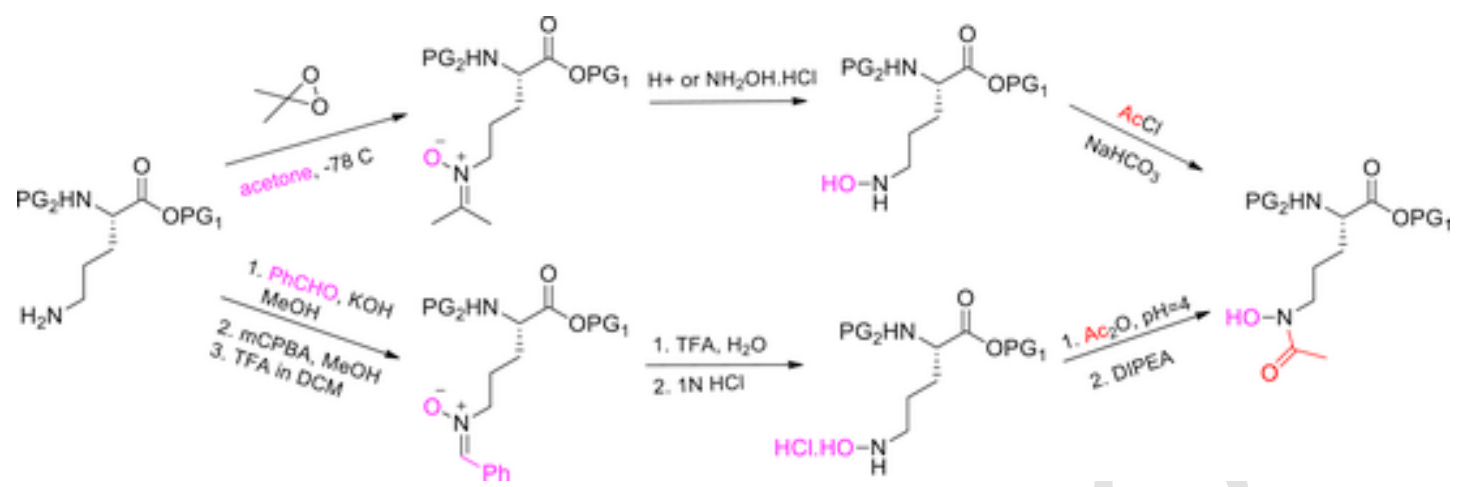

Scheme 3. Synthesis of ' $\mathrm{PG}_{1}$-Orn(acyl,OBz)-OPG ${ }_{2}$ ' building block through the imine-nitrone intermediates and using DMD or PhCHO [87].

Other syntheses reported the preparation of the hydroxamate Orn starting from different amino acids. A full synthesis of ferrichrome in 1969 described the conversion of $\delta$-nitro norvaline (non-branched Val) into $\delta$-N-hydroxy ornithine by reducing the nitro group with zinc in an aqueous ammonium chloride solution [90,91] (Scheme 4). Another protocol included the conversion of the $\mathrm{COOH}$ side chain of glutamic acid to $\mathrm{OH}$ then its attachment to a protected simple hydroxamic acid (blue route in Scheme 1) using diisopropyl azodicarboxylate and triphenyl phosphine [85] (Scheme 4) (see Scheme 5).

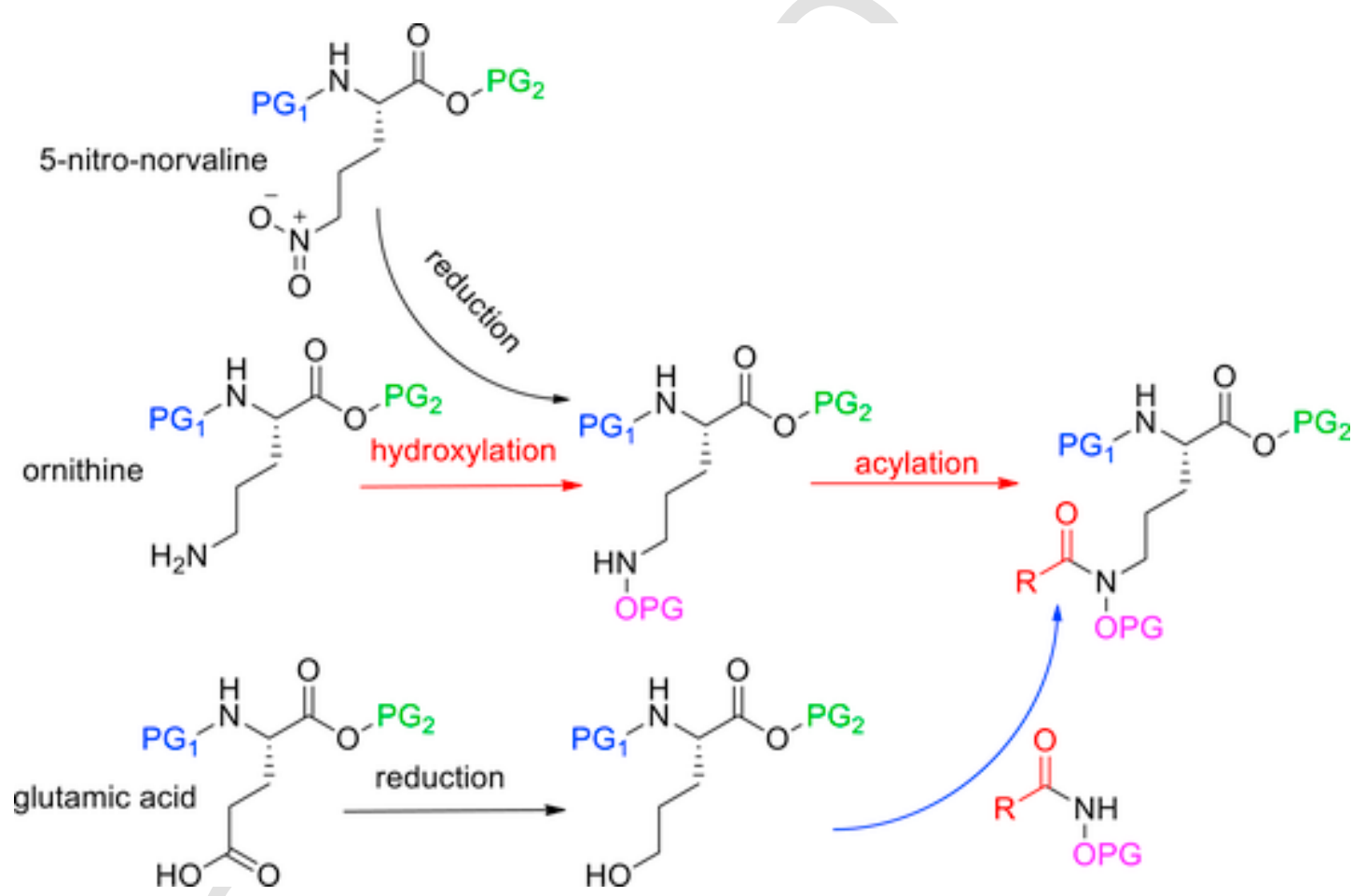

Scheme 4. Synthesis of ' $\mathrm{PG}_{1}-\mathrm{Orn}(\mathrm{acyl}, \mathrm{OBn})-\mathrm{OPG}_{2}$ ' starting from 3 different amino acids.
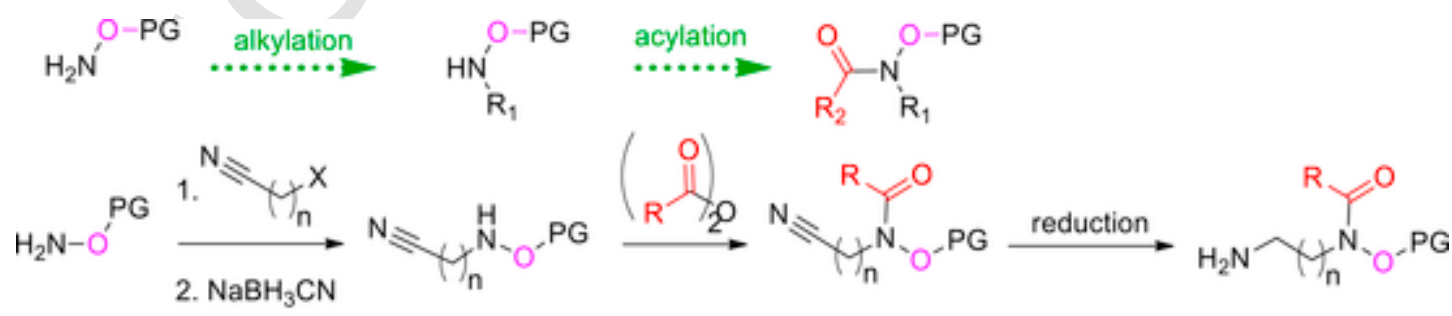

Desferrioxamine, $\mathrm{R}=\mathrm{CH}_{3}$ or $\left(\mathrm{CH}_{2}\right)_{2} \mathrm{COOH}, \mathrm{n}=3, \mathrm{X}=\underset{\text { II }}{\mathrm{O}}$

Bisucaberin, $\mathrm{R}=\left(\mathrm{CH}_{2}\right)_{2} \mathrm{COOH}, \mathrm{n}=4, \mathrm{X}={ }_{4} \mathrm{Cl}$ 


\subsubsection{Synthesis of N-5-aminopentyl-N(hydroxy)-succinic acid building} block

Reported syntheses of N-5-aminopentyl-N(hydroxy)-succinamic acid building unit started with the protected hydroxylamine, followed by an alkylation step with a cyano aldehyde (4-cyanobutanal) as in the preparation of desferrioxamine B [93], or a haloalkane nitrile (5-chloro valeronitrile) as in the synthesis of bisucaberin [94] (see scheme 5). The prepared cyanoalkylhydroxylamine is divided into two parts, the nitrile group in one of them is reduced to an amine group and acylation is done using succinic anhydride (the route followed is shown by green dashed lines, Scheme 1). The same route was reported for the synthesis of alcaligin but with a shorter alkyl part to prepare the N-5-aminobutyl-N(hydroxy)-succinic acid [95].

\subsubsection{Synthesis of other hydroxamate building blocks}

In some artificial siderophores, the hydroxamate moiety was embedded in the backbone through $\alpha$-N-hydroxy amino acids prepared indirectly from other closely related acids. For example, $\alpha$-benzyloxyglycine was obtained by reacting bromoacetic acid tert-butyl ester and O-benzylhydroxylamine [96]. N-benzyloxyalanine (or N-benzyloxyphenylalanine) was prepared starting from D-lactic acid (or D-phenyllactic) acid $t$-butyl ester by converting the $\alpha$-OH to a triflate intermediate, followed by the reaction with O-benzylhydroxylamine [97]. The $\mathrm{SN}_{2}$ attack of the benzolyxyamine resulted with inverted configuration of $\alpha$-carbon. The amide bond was then formed by condensing the hydroxylated $\alpha-\mathrm{N}$ with an $\alpha-\mathrm{COOH}$ of another amino acid using an effective form of activated acid $[96,98]$. All these methods followed the green route of Scheme 1 by introducing the alkyl part into a previously prepared benzyl protected-hydroxyl amine (Scheme 6).
A more recent study hydroxylated the $\alpha-\mathrm{N}$ of the amino acid with m-CPBA after alkylating it with bromoacetonitrile (converting it temporarily into a secondary amine prior to hydroxylation, making the latter much more efficient) [99] (Scheme 6).

\subsubsection{Incorporating the hydroxamate building block into the backbone}

\subsection{Binding affinity towards iron}

Siderophores, in general, form strong complexes with Fe (III), with thermodynamic formation constants $\beta$ up to $10^{49}$ for the tris-catecholate enterobactin (Fig. 1), compared to $10^{25}$ for EDTA, a widely used complexing agent for metal ions. Tris hydroxamate siderophores also show high formation constants of $\sim 10^{30}$. In the fully deprotonated forms of ligands (at highly basic conditions), catecholate siderophores show greater binding to $\mathrm{Fe}(\mathrm{III})$ than hydroxamates (the difference in $\log \beta$ values can go up to 19 units, which means that the concentration of the catecholate-Fe complex is $10^{19}$ times that of hydroxamate-Fe under same conditions). However, at physiological $\mathrm{pH}(\mathrm{pH}=7.4)$, the binding affinity (reflected by $\mathrm{pFe}^{3+}$, which equals $-\log \left[\mathrm{Fe}^{3+}\right]_{\text {free }}$ at $\mathrm{pH}=7.4$, $\left[\mathrm{Fe}^{3+}\right]$ total $=10^{-6} \mathrm{M}$ and $\left.[\text { Ligand }]_{\text {total }}=10^{-5} \mathrm{M}\right)$ of the two siderophores is comparable (the difference in binding affinities is much lower). This observation is attributed to the acidic character of the hydroxamates, a feature that increases the proportion of deprotonated molecules (ready to bind to $\mathrm{Fe}(\mathrm{III})$ ) of hydroxamate compared to catecholate.

For comparative purposes, Table 3 shows the formation constants and iron affinity for several siderophores with different chelating groups. a)

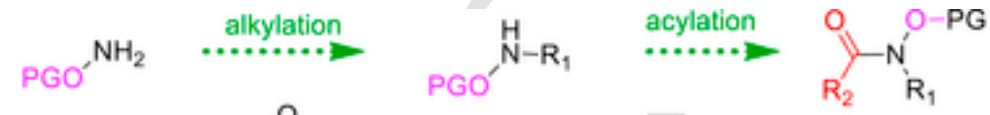<smiles>CCCCONCC(=O)OCCCC</smiles><smiles>[10BH2][18O]N</smiles>

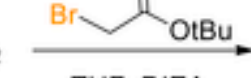
THF, DIEA<smiles>CCCCO[C@@H](C)C(=O)CCCC</smiles>

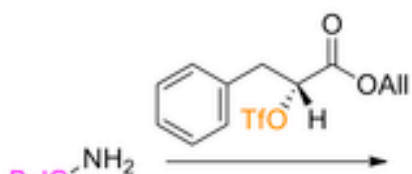<smiles>CCCCOC(=O)[C@H](C)NOC(=O)OC</smiles>
Peptide elongation $\mathrm{BzIO}^{\prime}$<smiles>O=C(OCc1ccccc1)C(Cc1ccccc1)C(=O)OCc1ccccc1</smiles>

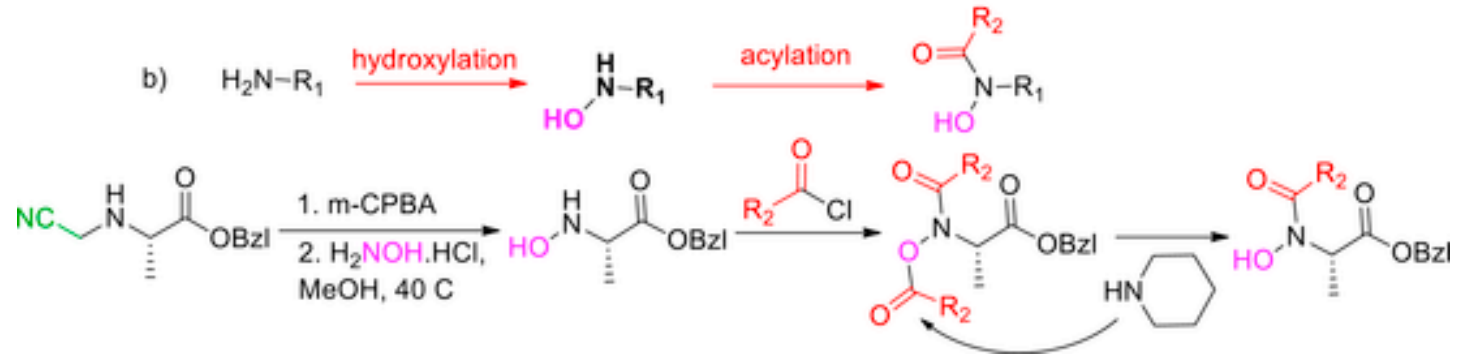


Table 2

Reported strategies used for the incorporation of hydroxamate building blocks into the siderophore backbone.

\begin{tabular}{|c|c|c|c|c|c|}
\hline $\begin{array}{l}\text { Hydroxamate } \\
\text { Building unit }\end{array}$ & Siderophore & $\begin{array}{l}\text { Entry } \\
\text { No. }\end{array}$ & Synthetic Strategies & & Ref. \\
\hline \multirow[t]{5}{*}{ Ornithine-derived hydroxamate siderophores } & Pyoverdin & $\begin{array}{l}\text { Fig. } \\
1\end{array}$ & $\mathrm{Fmoc} / \mathrm{tBu}$ & $\begin{array}{l}\text { Super acid- } \\
\text { labile Rink }\end{array}$ & {$[88]$} \\
\hline & Amphibactin-T & 10 & $\mathrm{Fmoc} / \mathrm{tBu}$ & $\begin{array}{l}\text { CTC- } \\
\text { polystyrene } \\
\text { resin (solid } \\
\text { phase) }\end{array}$ & [92] \\
\hline & Albomycin & 3 & $\mathrm{Fmoc} / \mathrm{tBu}$ & $\begin{array}{l}\text { Solution } \\
\text { phase }\end{array}$ & [89] \\
\hline & Ferrichrome & 1 & Boc/Bzl & $\begin{array}{l}\text { Solution } \\
\text { phase }\end{array}$ & [90] \\
\hline & $\begin{array}{l}\text { DIG-siderophore } \\
\text { (conj.) }\end{array}$ & & $\begin{array}{l}\text { Functionalizing the Orn } \\
\text { as building block or its }\end{array}$ & $\begin{array}{l}\text { Solution } \\
\text { phase }\end{array}$ & [87] \\
\hline \multirow[t]{3}{*}{ N-hydroxy diaminoalkane derived sidrophores } & Desferrioxamine & 6 & $\begin{array}{l}\text { Metal-templated Cyclic } \\
\text { Trimerization }\end{array}$ & $\begin{array}{l}\text { Solution } \\
\text { phase }\end{array}$ & [100] \\
\hline & Bisucaberin & 37 & Boc/Bzl & $\begin{array}{l}\text { Solution } \\
\text { phase }\end{array}$ & [101] \\
\hline & Alcaligin & 7 & $\begin{array}{l}\text { Diphenylphosphoryl } \\
\text { azide (DPPA) + triethyl } \\
\text { amine }\end{array}$ & $\begin{array}{l}\text { Solution } \\
\text { phase }\end{array}$ & [95] \\
\hline
\end{tabular}

\subsection{Applications of hydroxamate molecules and hydroxamate siderophores}

Hydroxamic acids have found many applications in medical and agricultural practices [109] and as probes [1,3]. Their medical use can be therapeutic or diagnostic [110]. The presence of hydroxy substituents on the amide bonds of an active peptide enhances its stability against enzymatic degradation [96]. Furthermore, hydroxamic acids inhibit methionine aminopeptidase (MetAP), an essential enzyme in protein synthesis in a variety of organisms. This inhibition enables the use of hydroxamic acids as potent antibacterial or antitumor agents $[96,111]$. Also, these acids have the potential to inhibit metalloproteases and HIV protease, and they show activity in immune suppression [96].

As metal chelators, Desferal, the brand name of desferrioxamine B (6), was the first drug used for the treatment of metal poisoning, namely iron overloading $[22,112]$. Also, the hydroxamate groups have shown unprecedented activity against the growth of $P$. aeruginosa biofilms (which confer cells extra resistance to antibiotics by adhering in the form of a film) when they were combined with glycol motifs in a bifunctional molecule, in which the glycol targeted the adhesion of cells and hydroxamate deprived cells of iron [113].

In this review, we focus on and discuss the use of hydroxamate siderophores as Trojan horses to overcome bacterial resistance to antibiotics.

2.4.1. HA siderophores-antibiotic conjugates (application as Trojan horses)

After being excreted and complexed to Fe(III), the loaded siderophores are recognized by specific protein receptors present on the microbial cell membrane. They are then transferred through specified cycles to their target inside the cell (cytoplasm or sometimes periplasm in some gram-negative bacteria). Fe(III) is then released form the siderophore through certain mechanisms $[11,12]$, reduced to $\mathrm{Fe}(\mathrm{II})$ and metabolized [8].

The microorganisms that produce hydroxamate siderophores have a special protein receptor, FhuA, embedded in their membranes to recognize and mediate the uptake of the iron-siderophore complex
$[11,16,114]$. FhuA may also be present in the membrane of other microorganisms that do not produce endogenous hydroxamate siderophores yet can take up the hydroxamate siderophores produced by other organisms [13].

Some studies have suggested that the protein receptors recognize and identify key points in the siderophore backbone. Others propose that recognition occurs via identification of the steric configuration of the e-donating atoms around the central iron in the inner coordination sphere $[13,17]$. The latter notion may explain how some species can take up iron from xenosiderophore complexes. A study by Shanzer's group suggested that the recognition takes place in two domains: first, the configuration of the complex around iron; and second, the spatial orientation of the functional groups $(C=O)$ with respect to the inner coordination sphere $[115,116]$. It is likely that microorganisms have two types of receptors-specific ones to identify endogenous siderophore-iron complexes and more general ones that identify the core of the xenosiderophore-iron complexes.

Some bacterial strains exploit the greed for theft of other species by producing and attaching a siderophore chelator to a microbiocidal moiety. The resulting conjugate is called a "sideromycin". These molecules are then released into the matrix as Trojan horses to poison competing opponent cells.

2.4.1.1. Natural conjugates (sideromycins) Natural sideromycins are highly specific against certain types of bacteria and are taken up through the same pathway as the corresponding type of siderophores with respect to the binding unit.The first reported sideromycin was grisein, discovered by Waksman's group in 1947 [23]. It was isolated from a strain of Streptomyces griseus. It showed antimicrobial activity against many strains of bacteria but its structure was not elucidated then and was partially characterized in 1951 [117]. Grisein was later reported as albomycin (3) [112]. Albomycins are the most widely known natural sideromycins. In 1951, Gause and Brazhnikova isolated an albomycin from Actinomyces suibtropicus, a species of streptomycetes [118]. It was found to strongly inhibit the growth of some gram-positive bacteria, such as $S$. aureus, $S$. pneumoniae and B. subtilis, as well as some gram-negative bacteria [112]. The activity of this albomycin was found to be ten times stronger than that of penicillin [118], and it was 
Table 3

Comparison of the thermodynamic constants for various representative tris-hydroxamate siderophores and their Fe(III) complexes with that of enterobactin.

\begin{tabular}{|c|c|c|c|c|c|}
\hline Siderophores & $\begin{array}{l}\text { Entry } \\
\text { no. }\end{array}$ & $\mathrm{pKa}$ & $\log \beta_{110}$ & ${ }^{\mathrm{a}} \mathrm{pFe}^{3+}$ & Ref \\
\hline $\begin{array}{l}\text { Enterobactin } \\
\text { (triscatecholate) }\end{array}$ & $\begin{array}{l}\text { Fig. } \\
1\end{array}$ & $\begin{array}{l}6.00 \\
7.50 \\
8.55\end{array}$ & 49 & 34.3 & {$[102,103]$} \\
\hline Ferrichrome & 1 & $\begin{array}{l}8.11 \\
9.00 \\
9.83\end{array}$ & 29.07 & 25.2 & {$[104,105]$} \\
\hline Ferricrocin & 2 & $\begin{array}{l}8.14 \\
9.01 \\
9.92\end{array}$ & 30.4 & 26.5 & [106] \\
\hline Ferrioxamine B & 6 & $\begin{array}{l}8.39 \\
9.03 \\
9.70\end{array}$ & 30.6 & 26.6 & [104-106] \\
\hline Basidiochrome & 30 & $\begin{array}{l}\text { Not } \\
\text { evaluated }\end{array}$ & 27.8 & 25 & [107] \\
\hline $\begin{array}{l}\text { Aquachelin-C (bi- } \\
\text { hydroxamate) }\end{array}$ & 40 & $\begin{array}{l}3.79 \\
(\mathrm{COOH}) \\
8.73 \\
(\mathrm{CONOH}) \\
9.52 \\
(\mathrm{CONOH})\end{array}$ & 31.4 & - & [108] \\
\hline $\begin{array}{l}\text { Marinobactin-D } \\
\text { (bi-hydroxamate) }\end{array}$ & 11 & $\begin{array}{l}3.75 \\
(\mathrm{COOH}) \\
8.47 \\
(\mathrm{CONOH}) \\
9.40 \\
(\mathrm{CONOH})\end{array}$ & $\begin{array}{l}\text { Not } \\
\text { evaluated }\end{array}$ & - & [108] \\
\hline $\begin{array}{l}\text { Marinobactin-E } \\
\text { (bi-hydroxamate) }\end{array}$ & 11 & $\begin{array}{l}3.85 \\
(\mathrm{COOH}) \\
8.89 \\
(\mathrm{CONOH}) \\
9.52 \\
(\mathrm{CONOH})\end{array}$ & 31.8 & - & [108] \\
\hline
\end{tabular}

${ }^{\mathrm{a}} \mathrm{pFe}^{3+}=-\log \left[\mathrm{Fe}^{3+}\right]_{\text {free }} \quad$ at $\quad \mathrm{pH}=7.4, \quad\left[\mathrm{Fe}^{3+}\right]$ total $=10^{-6} \mathrm{M}, \quad[\text { Ligand }]_{\text {to- }}$ tal $=10^{-5} \mathrm{M}$.

used in the Soviet Union as an antibiotic. Its structure was firmly established by Benz and coworkers in 1982 [24]. Similarities between grisein and albomycin that led to conclude that they are the same compound have been discussed in the literature [119]. Other examples of hydroxamate sideromycins are salmycins and ferrimycins (Table 4).All bacteria susceptible to the microbicidal activity of these hydroxamate sideromycins were found to have the FhuA receptor in their membranes. These sideromycins function better under iron starvation conditions than under conditions of sufficiency [3]. Iron starvation can be achieved by using biostatic agents (strong chelators that bind iron tightly).In addition to these sideromycins, another seryl tRNA synthetase inhibitor, SB-217452 [122], was isolated from a Streptomyces species. Although structural characterization showed that SB-217452 contains the same nucleoside moiety present in albomycin, it showed very weak antibacterial activity compared to the latter. This can be explained by the fact that SB-217452 does not contain the chelator moiety that mediates the uptake of albomycin $[13,122]$. This example and many others clearly demonstrate the role played by the chelator moiety in overcoming the low permeability of the pathogenic cell wall towards the bactericidal moiety alone.Albomycin (3) consists of a linear Orn-derived tri hydroxamate. The tri peptide is linked through its $C$-terminus to a glycoside entity by a di-seryl linker. When the competing bacteria internalize the conjugate-iron complex, peptidases release the warhead, thus inducing bacterial death [13] (Fig. 3-A). Ferrimycin (66) resembles the ferrioxamine family in its chelating unit, which is a linear non- peptidyl tris-hydroxamate derived from alternative N-hydroxy-diaminopentane and succinic acid with a 4-amino-5-hydroxybenzamide linkage to an iminoester-substituted lactam antibiotic [112]. Salmycin consists of danoxamine siderophore (9) attached to an aminoglycoside through a succinic linker [121]. When the hydroxamate moieties are engaged with iron complexation, the payload remains attached to the conjugate. Once the reductase of the cell frees the iron, the protonated hydroxamate attacks the ester group causing a cyclization reaction that results in the release of the antibiotic. This only happens after the competing cell obtains the iron from the stolen complex $[13,123]$. The mechanism of drug release is shown in Fig. 3-B [123].Of note, the sideromycin-producing organism itself is not affected by the conjugate because it does not have a target for the warhead or the related enzyme that causes drug release [13]. Also, vulnerable bacteria can readily develop resistance against these sideromycins through the deletion of the hydroxamate membrane receptor [14].

2.4.1.2. Artificial conjugates mimicking the natural ones The activity of the natural sideromycins opened the door for research into new conjugates. In this regard, attention was turned to tuning the structure of the chelators and varying the antimicrobial moiety, thereby providing promising tools for tackling fatal multidrug-resistant bacteria.The first synthetic conjugate 85 was reported by Zahner in 1977 [13]. He hybridized DFO B with a sulfonamide directly through an amide bond (no linker) between the available primary amine of the chelator moiety and the carboxyl of the sulfonamide. Many artificial hybrids containing hydroxamate chelators have been reported to date (Table 5), with cargos varying between cephalosporines, flouroquinolines and others. However, none of the hydroxamate-drug hybrids have yet been approved as a drug. Cefiderocol (S-649266) is the first and only siderophore-drug conjugate to be authorized by the FDA (November 2019) [124]. This drug consists of a catechol chelating unit and a cephalosporin antibiotic cargo [125] (see section 3).In summary, conjugates 68-73 are semi synthetic sideromycins that share the same chelator moiety as albomycin (3) which is a linear Orn-derived tri hydroxamate. The antibiotic moieties in these conjugates varies between ß-lactams as in $\mathbf{6 8}$ and 69, and fluoroquinolones as in $\mathbf{7 0}$, attached to the $C$-terminal of the chelating peptide backbone. In conjugates 71-73, the antibiotics digoxigenin, biotin and virgimycin, respectively, are attached to the tripeptide backbone via different linkers through its N-terminals.Conjugates 74-77 are totally synthetic; the chelator moiety is an iso cyanuric acid-based tri Orn hydroxamate, inspired by the natural bi hydroxamate siderophore rhodotorulic (4). The antibiotic is directly attached to the acyl part of the hydroxamate, enabling the preparation of multi-warhead conjugates [142].Conjugates 78-82 were synthesized to illustrate the effect of linker on overall activity. All are containing the same chelator moiety, desferrioxamine $\mathrm{B}$, and ciprofloxacin antibiotic. The linkers vary from stable uncleavable succinic moiety $\mathbf{7 8}$ to esterase-cleavable $\mathbf{7 9}$, phosphatase-cleavable $\mathbf{8 0}$ and reductase-cleavable $\mathbf{8 1}$, ending with thiol-maleimide linker 82. The mechanisms of drug release are shown in Fig. 4 [132]. Conjugates 82-84 share the same desferrioxamine B chelator, the same linker (thiol maleimide) and three different antibiotics.Conjugates 86-88 contain danoxamine analogue chelators with differing denticity (mono, bi and tri hydroxamate) and three different antibiotics attached through a stable linker.Conjugates 89-102 contain mixed chelators. Compounds 89-98 are biscatecholate-mono hydroxamate, with various antibiotic warheads, while 99-102 are pyoverdine-derived (bis hydroxamate, mono catecholate) chelators attached to a range of drugs through different linkers at distinct positions of the pyoverdine scaffold.Conjugate 106 is mycobactin chelator (employing lysine residue as the hydroxamate-bearing moiety) attached to the antibiotic artemisinin.

2.4.1.2.1. Summary of the antibacterial activity of these conjugates Most of these conjugates had moderate to low antibacterial activity. Conjugates with ß-lactams showed better performance than those with non 
Table 4

Natural hydroxamate sideromycins, chelator moieties are shown in black and purple, linkers in green and antibiotic moiety in red.

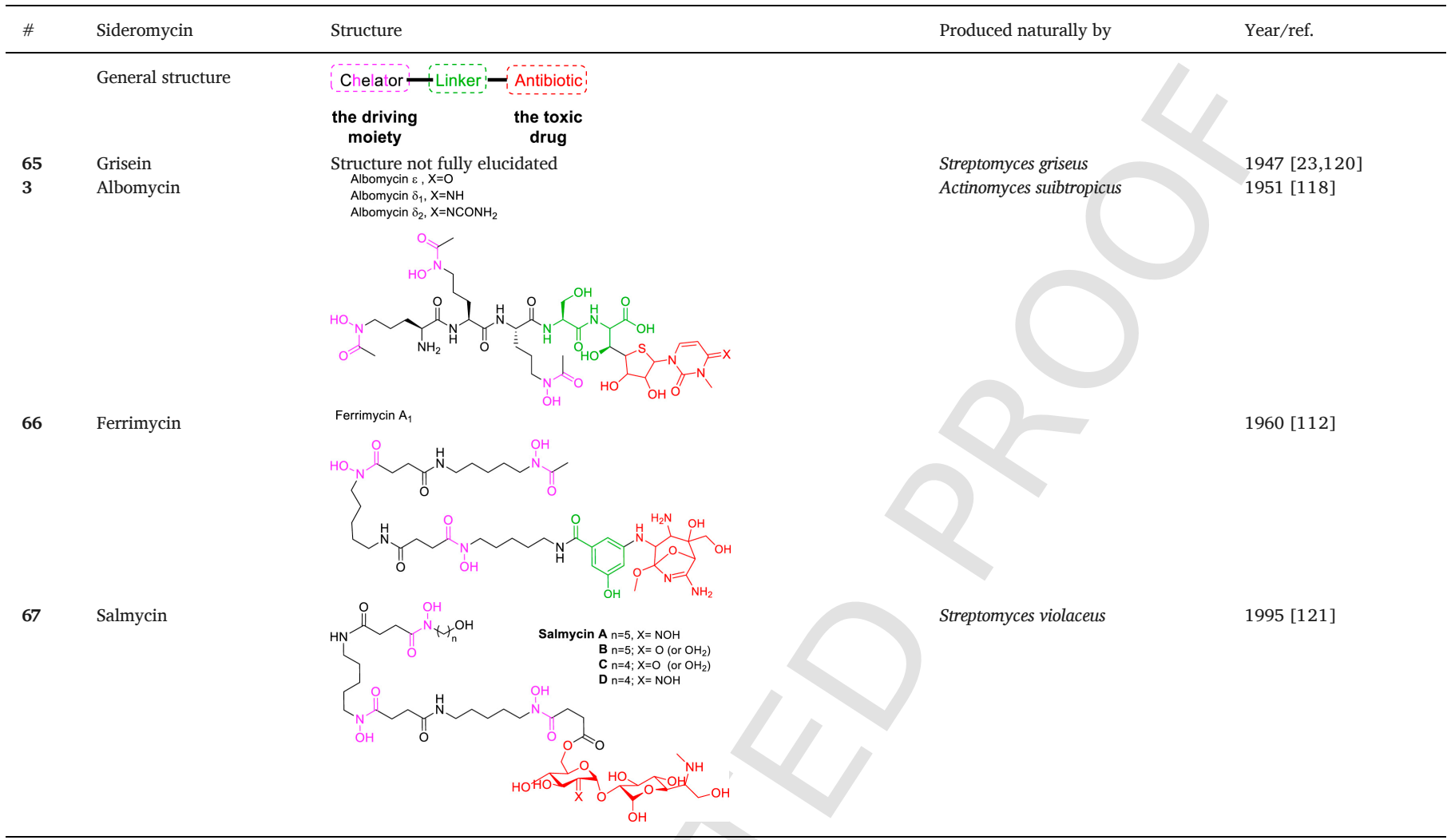

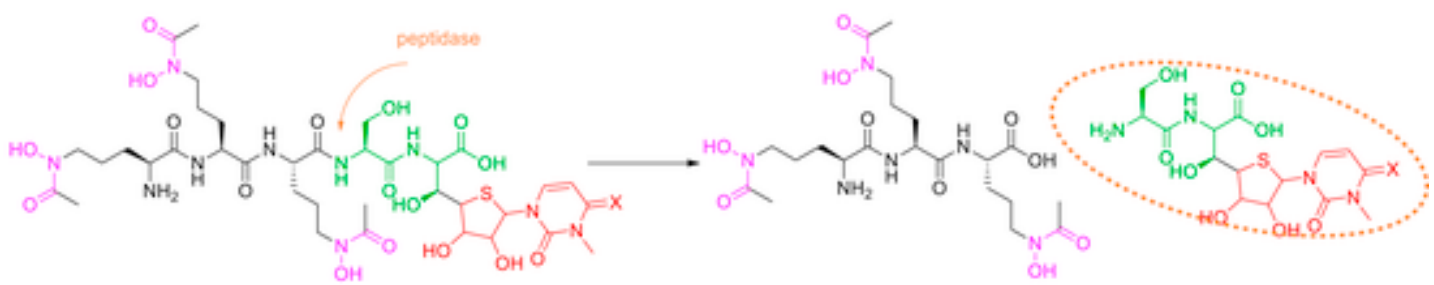

b

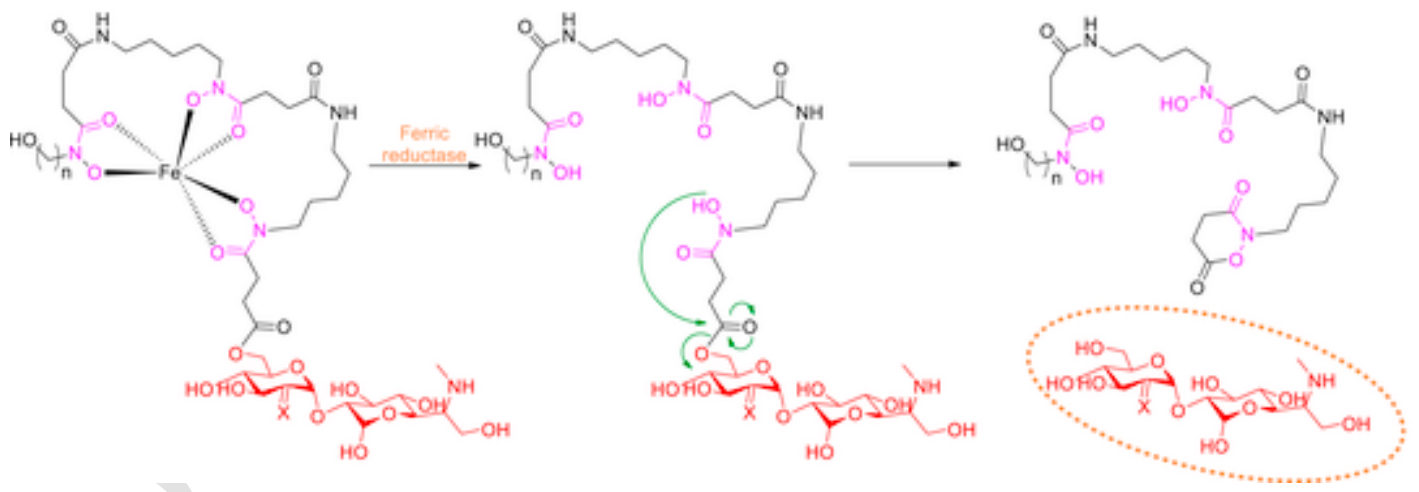

Fig. 3. Possible mechanisms for drug release from sideromycin: a) albomycin and b) salmycin.

ß-lactams [14]. The activity of the conjugates under iron-deficient conditions was enhanced but was lower than that of the parent antibiotic alone in most cases. This observation may be attributable to premature release, non-suitable substrates for enzymatic cleavage, or readily de- veloped resistance [135]. The modification of linkers (trimethyl lock) in 79-80 did not achieve better results.Here are some examples with the main conclusions learned from their study:Conjugates 86-88 showed that the denticity of the chelator is crucial, where it should 
Table 5

Artificial hydroxamate siderophore-drug (SD) conjugates, chelator moieties are shown in black and purple, linkers in green and antibiotic moiety in red.

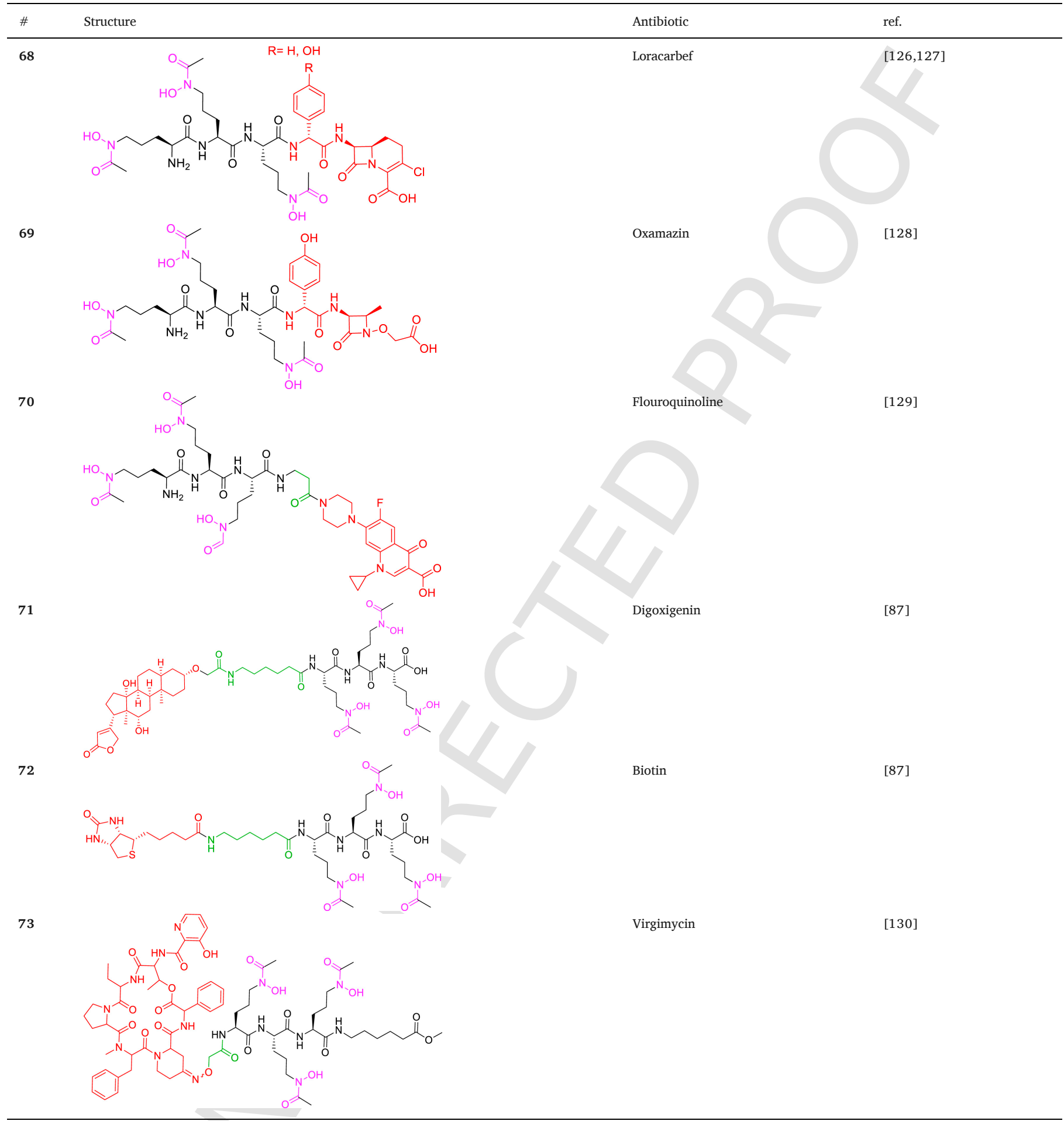




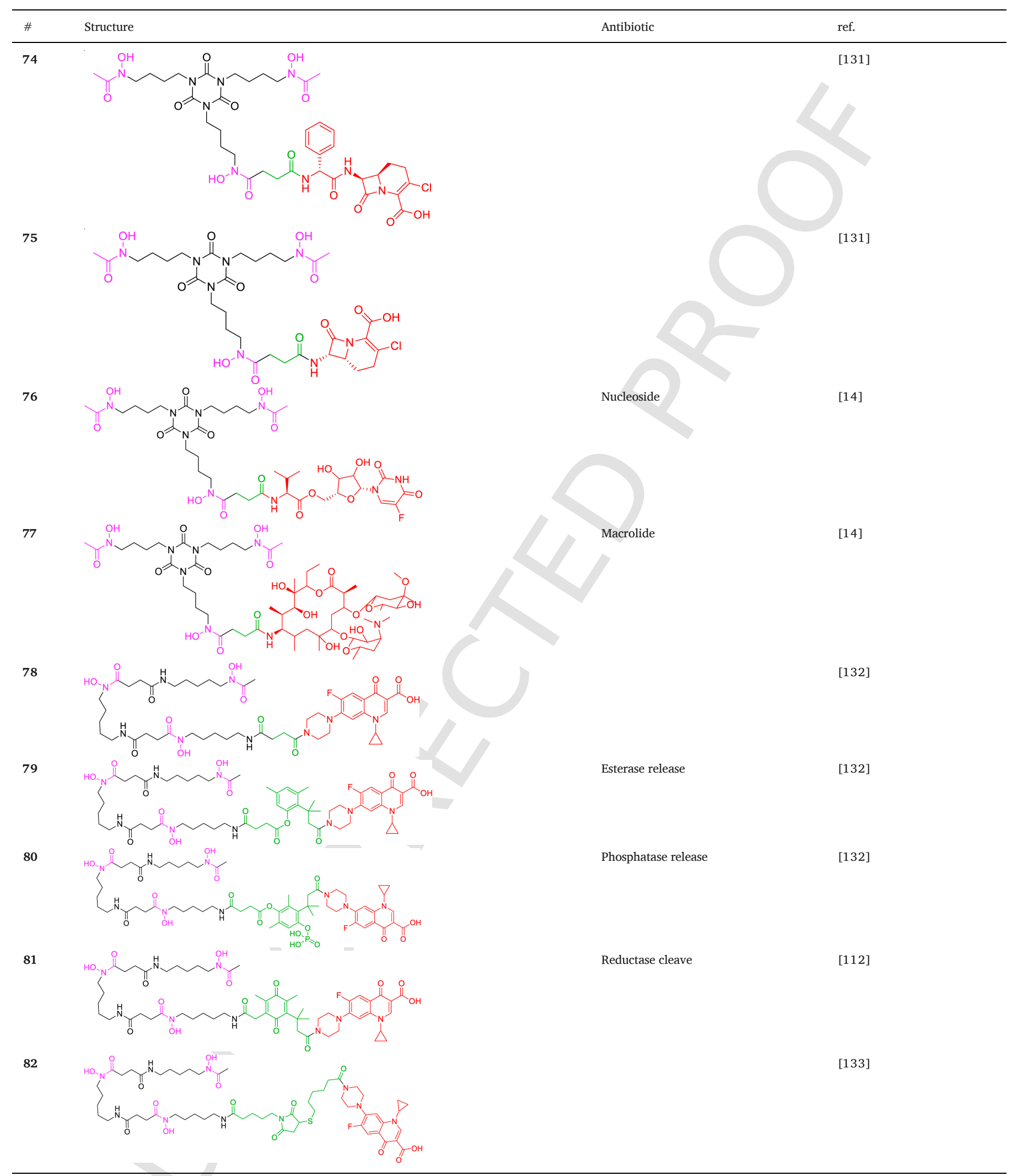




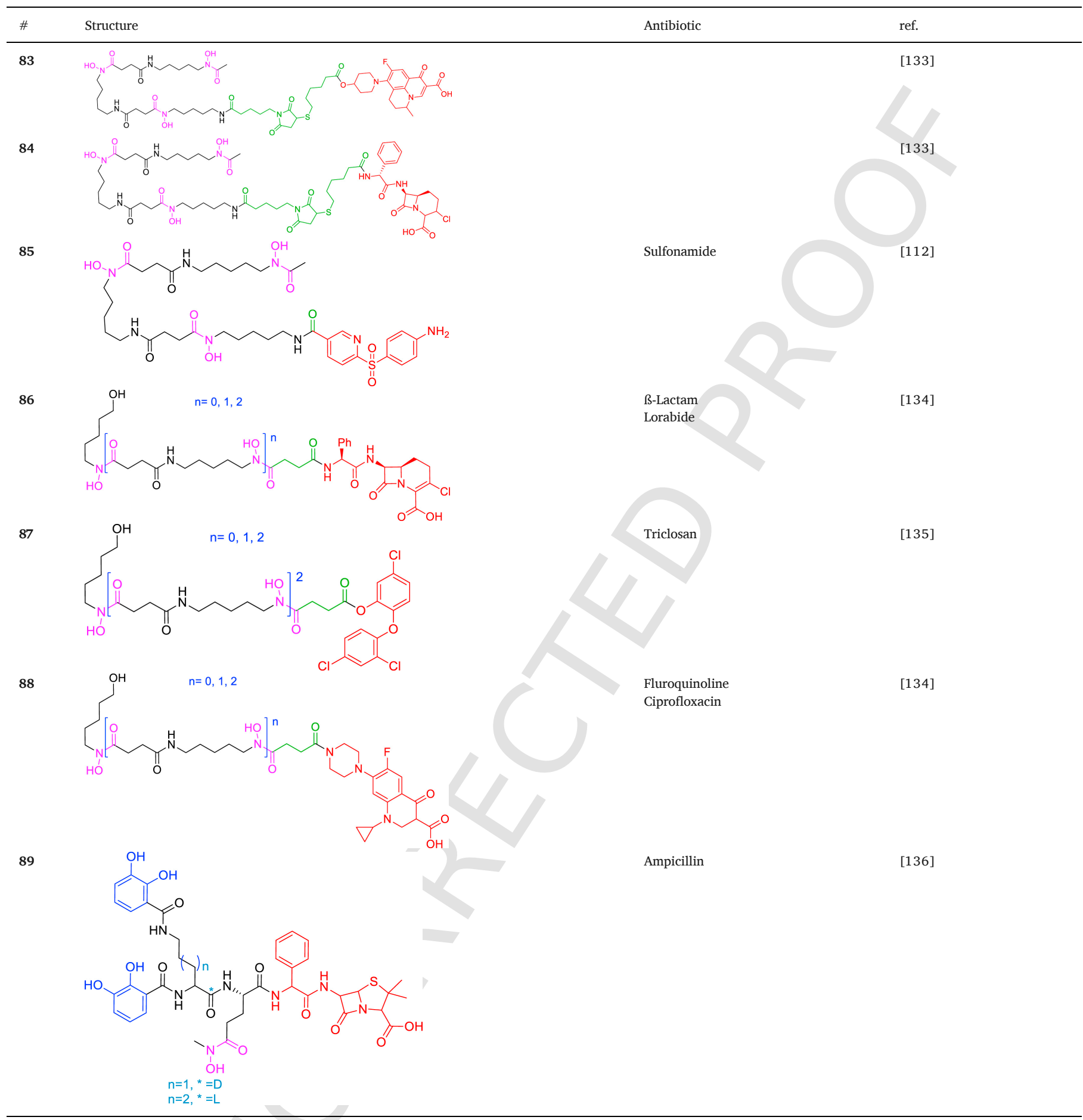


D. Al Sharer et al. / European Journal of Medicinal Chemistry $x x x(x x x x) 112791$

23

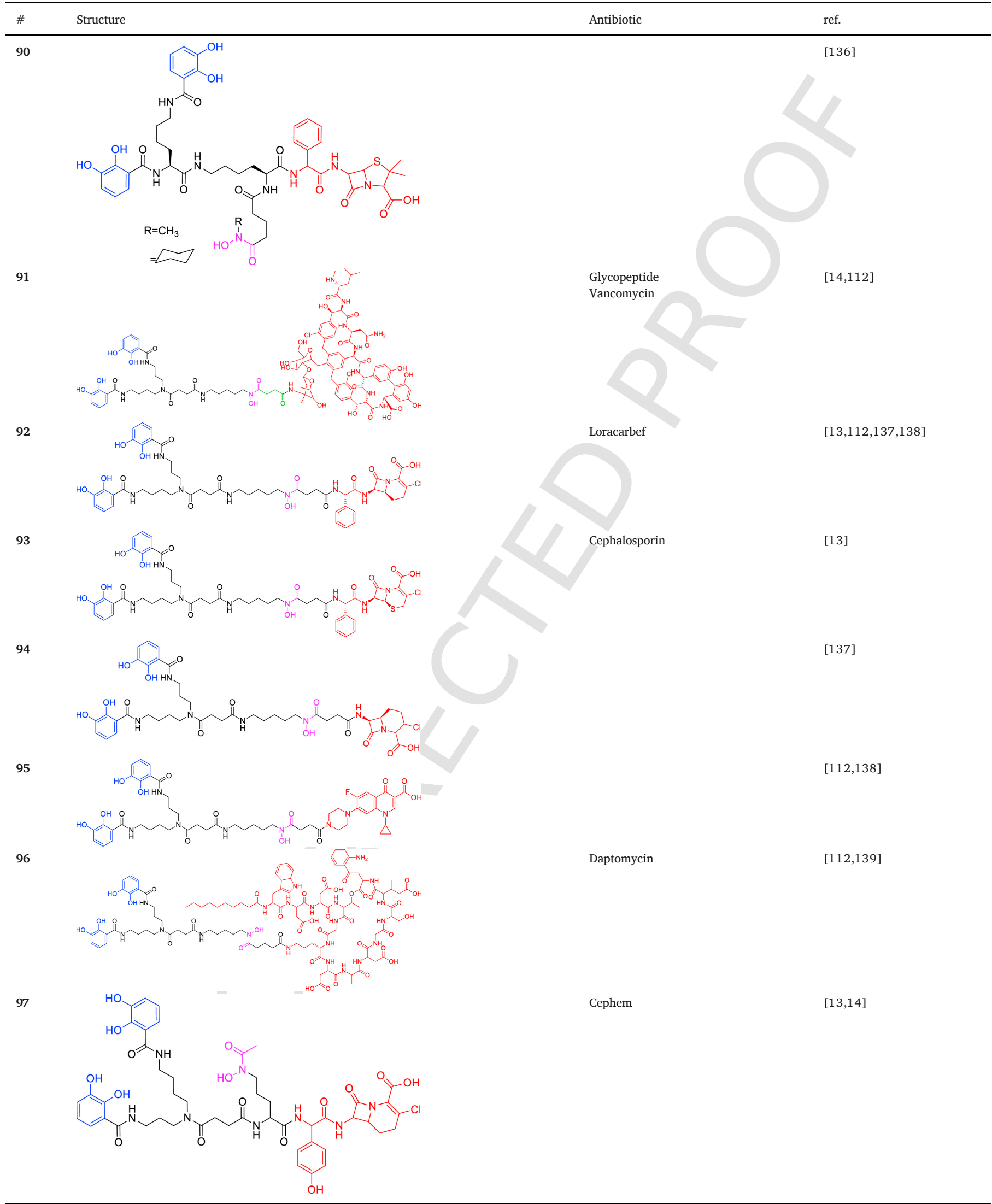




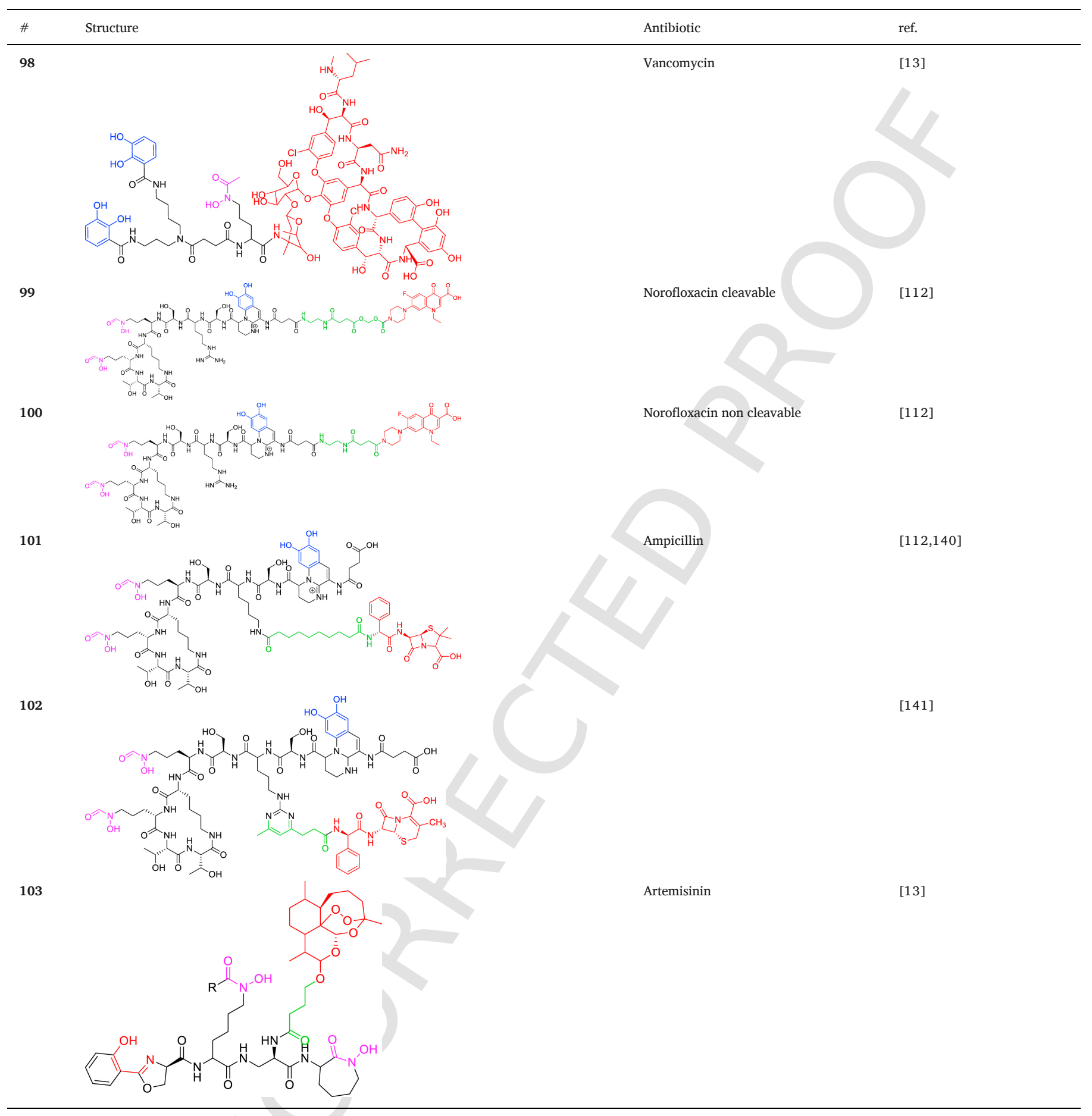

form a 1:1 complex with Fe(III) to actively transport the conjugate $[134,135]$.Conjugate 92 employs a bis catecholate-mono hydroxamate chelator that is analogous to fimsbactin (a siderophore produced by $A$. baumannii), the chelator is conjugated to loracarbef. It shows high activity against $A$. baumannii, again demonstrating the vulnerability of a bacterium against a hybrid of its own siderophore (advantage of endogenous over xenogenous siderophores). Furthermore, 92 mediates uptake through two receptors in E. coli, namely Cir (for the catechol) and FhuA (for the hydroxamate) [14,112].The same mixed bis-catecholate mono-hydroxamate chelator hybridized with a ciprofloxacin warhead as in 95, shows no activity against A. baumannii [112,134], emphasizing the importance of harmony between the uptake cycle of the chelator and the target of the antibiotic. The cycle of this conjugate ends in the periplasm, while the target of ciprofloxacin (unlike the loracarbef in 92) is the cytoplasm, thereby explaining the lack of activity of 95.A strong promising example is conjugate 96 , which conferred the gram-positive antibiotic daptomycin activity against some gram-negative bacteria $[138,139]$. This conjugate revealed that that large molecules (such as daptomycin $>500 \mathrm{Da}$ which cannot diffuse into the cell like the smaller molecules) can also be transported into the cell through specific iron-mediated receptors [112].Conjugate 103 was highly specific to M. tuberculosis. The chelating moiety in conjugate 103 resem- 


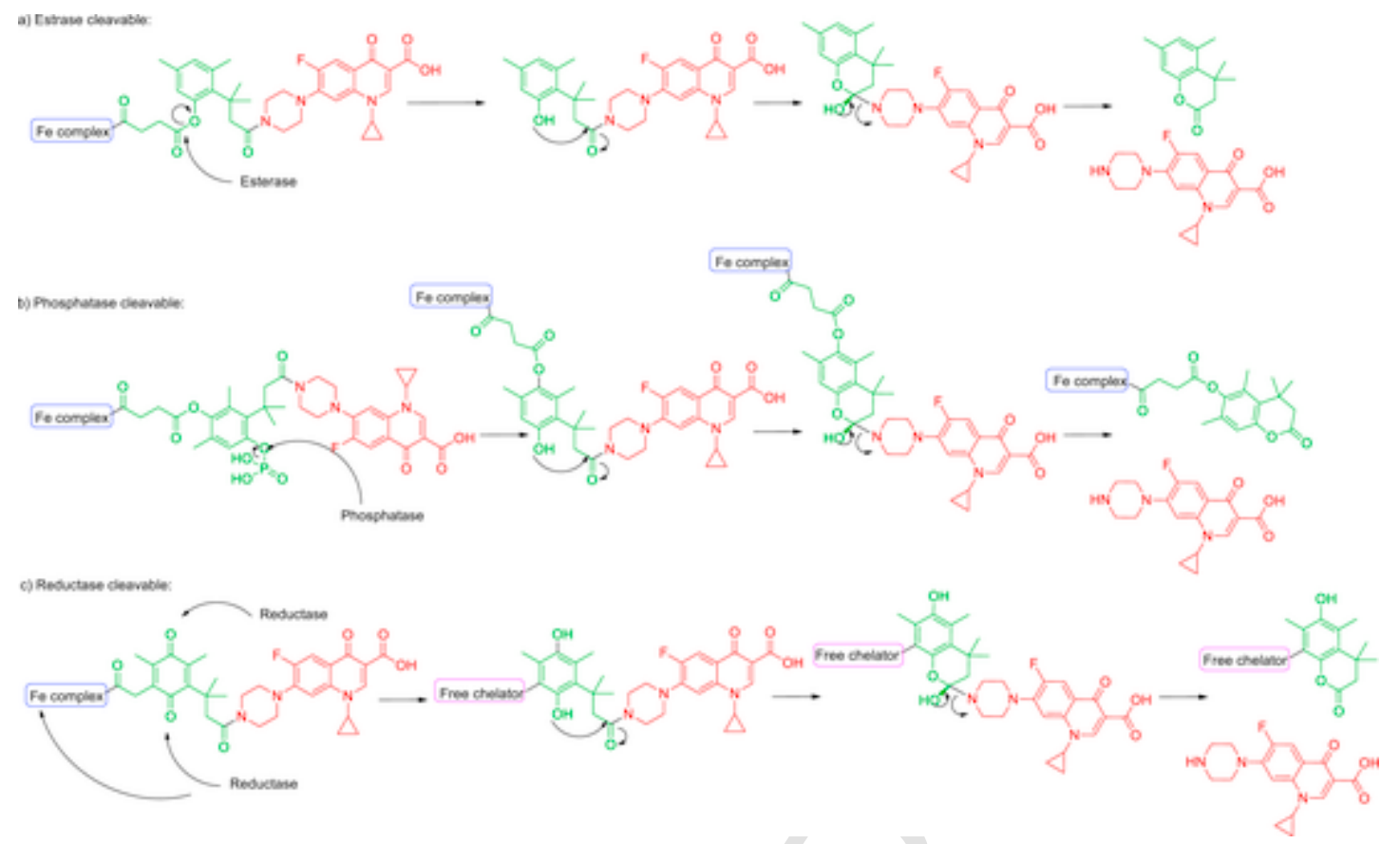

Fig. 4. "Trimethyl lock" mechanism of drug release in conjugates: a) 79 b) 80 [132] and c) 81 [13].

bles mycobactin, the siderophore produced by M. tuberculosis. However, 103 did not attack other gram-positive or -negative bacteria [13,112]. Again, this observation indicates that the use of the pathogen's own siderophore may be useful. The same conclusion was drawn from pyoverdine-derived conjugate 101 against the pyoverdine producer $P$. aeruginosa [140].

2.4.1.3. Rational design for choice of artificial siderophore-drug conjugates Traditional antibiotics are classified into four groups on the basis of their cellular targets. The targets are cell wall assembly (as for $ß$-lactams and glycopeptides), protein synthesis (as for aminoglycosides and macrolides), DNA/RNA replication (as for flouroquinolines and sulfonamides) and membrane disruption (as for lipodepsipeptides; daptomycin) [112]. Small antibiotics ( $<500 \mathrm{Da}$ ) enter the cell by passive diffusion through the porins in the cell wall of gram-negative bacteria and they are usually broad spectrum. On the other hand, glycopeptides and daptomycin are active only against gram-positive bacteria, with targets present on the outer part of the cell [112]. Hybridizing these antibiotics with siderophores can broaden or narrow the spectrum of activity of the antibiotic warhead.

2.4.1.3.1. Choosing the chelator The chelator of choice depends on the pathogen targeted, its outer membrane protein receptors (what types of siderophores it can recognize), and the iron cycle (where Fe(III) is released-in the cytoplasm or periplasm) [135]. For example, trihydroxamate is suitable to drive cytoplasmic drugs while biscatechocalate-hydroxamate is suitable for periplasmic drugs for gram-negative bacteria. 2.4.1.3.2. Role played by the linker Linkers play a critical role in determining the efficiency of the conjugate. Premature release of the warhead or halting it back from attacking the target may fail the whole process. The choice of linker depends on the abovementioned factors. Several types have been reported, some of which have been mentioned before. Another kind of chelator is ß-lactam as a linker attached to any type of antibiotic. The release mechanism depends on the attack of ß-lactamase to free the other antibiotic payload [13].

2.4.1.3.3. Choosing the antibiotic The antibiotic warhead target determines where the release takes place, and, consequently, the type of linker to be used. Even when taking all factors carefully into consideration, the bacterial fast development of resistance remains the biggest challenge.

\subsubsection{Other hydroxamate siderophore conjugates}

In all the previous conjugates mentioned, the chelating units are the moiety that drives them towards the target and the payloads are the antibiotics. Hydroxamate chelators can also be used in other conjugates in which an antibody is the driving moiety and a radiolabelled metal-chelator complex is the cargo used for imaging [113,143] (Fig. 5).

\section{Cefiderocol (FETROJA®): the first siderophore-drug conjugate in the market}

Cefiderocol (previously known S-649266) is a novel catechol-based siderophore that targets gram-negative bacteria, including strains with carbapenem resistance, via a Trojan horse active transport mechanism $[125,144]$. The aminoacyl catechol moiety is attached with a di-methylene linker to the pyrrolidine ring of the antibiotic [144,145] (Fig. 6).

The structure of the payload in cefiderocol combines the features of the antibiotics ceftazidime and cefepime, thereby boosting activity against gram-negative bacteria, as well as stability. The quaternized $\mathrm{N}$-methyl-pyrrolidine and the carboxylate moieties of cefiderocol form a zwitterion that enhances water solubility, degradation resistance, and capacity to rapidly penetrate the outer cell membrane of gram-negative bacteria [146]. GR69153 (cefetecol), M - 14659 and S-9096 are other catechol-cephalosporine conjugates that showed strong antibacterial activity in vitro, but were not successful in vivo [145].

Cefiderocol was approved by the FDA on November 14, 2019 [124]. It is used for the treatment of complicated urinary tract infections (cUTI), including pyelonephritis caused by susceptible gram-negative microorganisms. It is administered intravenously. It has some reported adverse effects, including diarrhea, infusion site reactions, constipation, rash, candidiasis, cough, elevations in liver tests, headache, hypokalemia, nausea, and vomiting [147].

\section{Conclusion}

Forty years of research have been devoted to the synthesis and use of sideromycins to tackle pathogens. Among these conjugates, only one has reached the market, namely Cefiderocol, which was approved by the FDA in 2019. Although Cefiderocol contains a catechol (not a hy- 


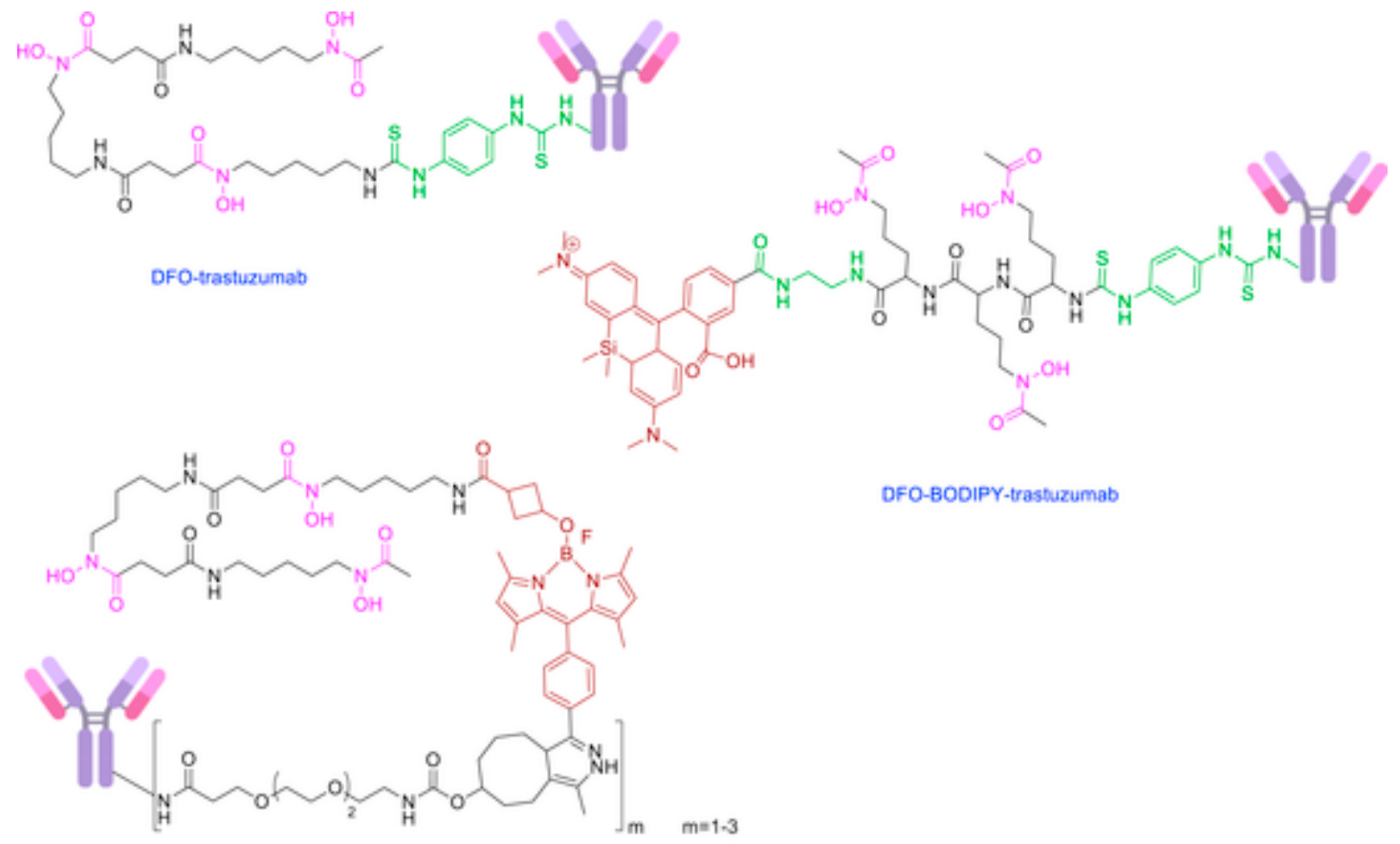

SIR-LDFC-trastuzumab

Fig. 5. Hydroxamate chelator-antibody conjugates for imaging applications.<smiles>CC(C)(O/N=C(\C(=O)N[C@@H]1C(=O)N2C(C(=O)[O-])=C(C[N+]3(CCNC(=O)c4ccc(O)c(O)c4Cl)CCCC3)CS[C@H]12)c1csc(N)n1)C(=O)O</smiles>

Fig. 6. Chemical structure of Cefiderocol.

droxamic) binding unit-the field remains open for the development of others. No other reported artificial conjugates have been commercialized to date, but they have all contributed to bringing the pieces of the puzzle together. Inspired by albomycins, ferrimycins and salmycins, hydroxamate-based siderophores are well positioned to achieve success. While the full picture of successful conjugate design and development is gaining clarity, more research efforts are required to optimize the technology.

\section{Declaration of competing interest}

Developing Multi-drug resistance in bacteria threatens human health when entering the post-antibiotic era. Iron acquiring gates supply bacteria with its nutrient, iron (III) by iron carrying molecules
(Siderophores). Using this strategy, siderophore-antibiotic conjugates (sideromycins) internalize the drug into the bacterial cell through iron gates, release the drug inside the cell and kill it. The most famous natural sideromycins (Albomycin, Salmycin, Ferrimycin) chelate iron (III) through their hydroxamate moieties, which also mediate the recognition and up take. An insisting need to understand the full picture behind their potency lead to the writing of this review. Most recent natural hydroxamate siderophore, chemical synthesis of building blocks, conclusions from the artificial sideromycins trials are all discussed thoroughly in this review.

In our opinion, this is a fully transversal review, which should be of interest to a broad scientific audience. Thus, synthetic chemists can find rich information about natural siderophores and comprehensive synthetic source for building blocks syntheses. 
Microbiologists will have access to the detailed structure and producing species for almost all hydroxamate siderophores isolated in the last two decades. It also helps biochemists with the rational relation between the choice of each of the bacteria, chelator, linker, antibiotic and the antibacterial activity, concluded from literature. Finally, drug hunters could find inspiration for the development of new drug discovery programs.

We are confident that our work will be of interest to a large number of colleagues working in related fields and merit publication in Eur. $J$. Med. Chem.

\section{Acknowledgement}

The work carried out in the laboratory was funded in part by the following: the National Research Foundation (NRF) (\# 105892 and Blue Sky's Research Programme \# 120386) and the University of KwaZulu-Natal (South Africa); and Marató TV3 foundation 2018 (\#20183530). We thank Professor Miquel Viñas (University of Barcelona) for fruitful discussions.

\section{References}

[1] T.C. Johnstone, E.M. Nolan, Beyond iron: non-classical biological functions of bacterial siderophores, Dalton Trans. 44 (2015) 6320-6339, doi:10.1039/ c4dt03559c.

[2] Iron is the Future - Part One: everything you want to know about iron!https:// newsroom.posco.com/en/iron-future-part-one-everything-want-know-iron/\#: text $=$ Atomic\%20number\%2026\%20Fe\%2C\%20a.k.a., even\%20in\%20the\%20human\%20body22 August 2020

[3] G. Tonziello, E. Caraffa, B. Pinchera, G. Granata, N. Petrosillo, Present and future of siderophore-based therapeutic and diagnostic approaches in infectious diseases, Infect. Dis. Rep. 11 (2019) 8208, doi:10.4081/idr.2019.8208

[4] H. Drechsel, G. Jung, Peptide siderophores, J. Pept. Sci. 4 (1998) 147-181 DOI 1075-2617/98/030147-35.

[5] D.J. Raines, T.J. Sanderson, E.J. Wilde, A.K. Duhme-Klair, Siderophores, Reference Module in Chemistry, Molecular Sciences and Chemical Engineering, Elsevier, Waltham, 2015.

[6] K.D. Krewulak, H.J. Vogel, Structural biology of bacterial iron uptake, Biochim. Biophys. Acta 1778 (2008) 1781-1804, doi:10.1016/j.bbamem.2007.07.026.

[7] E. Clément, P.J. Mesini, F. Pattus, I.J. Schalk, The binding mechanism of pyoverdin with the outer membrane receptor FpvA in Pseudomonas aeruginosa is dependent on its iron-loaded status, Biochemistry 43 (2004) 7954-7965, doi:10.1021/bi049768c.

[8] I.J. Schalk, G.L.A. Mislin, Bacterial iron uptake pathways: gates for the import of bactericide compounds, J. Med. Chem. 60 (2017) 4573-4576, doi:10.1021/ acs.jmedchem.7b00554.

[9] M. Sandy, A. Butler, Microbial iron acquisition: marine and terrestrial siderophores, Chem. Rev. 109 (2009) 4580-4595, doi:10.1021/cr9002787.

[10] G.S. Tillotson, Trojan horse antibiotics-A novel way to circumvent gram-negative bacterial resistance?, Infect. Dis. Res. Treat. 9 (2016) 45-52, doi:10.4137/IDRT.S31567.

[11] K. Dhusia, A. Bajpai, P.W. Ramteke, Overcoming antibiotic resistance: is siderophore Trojan horse conjugation an answer to evolving resistance in microbial pathogens?, J. Contr. Release 269 (2018) 63-87, doi:10.1016/ j.jconrel.2017.11.001

[12] A. Gorska, A. Sloderbach, M.P. Marszall, Siderophore-drug complexes: potential medicinal applications of the 'Trojan horse' strategy, Trends Pharmacol. Sci. 35 (2014) 442-449, doi:10.1016/j.tips.2014.06.007.

[13] Y.M. Lin, M. Ghosh, P.A. Miller, U. Mollmann, M.J. Miller, Synthetic sideromycins (skepticism and optimism): selective generation of either broad or narrow spectrum Gram-negative antibiotics, Biometals 32 (2019) 425-451, doi:10.1007/s10534-019-00192-6.

[14] M.G. Page, Siderophore conjugates, Ann. N. Y. Acad. Sci. 1277 (2013) 115-126, doi:10.1111/nyas.12024.

[15] E.D. Brown, G.D. Wright, Antibacterial drug discovery in the resistance era, Nature 529 (2016) 336-343, doi:10.1038/nature17042.

[16] A. Pramanik, V. Braun, Albomycin uptake via a ferric hydroxamate transport system of Streptococcus pneumoniae R6, J. Bacteriol. 188 (2006) 3878-3886, doi:10.1128/JB.00205-06.

[17] A. Shanzer, C.E. Felder, Y. Barda, Natural and biomimetic hydroxamic acid based siderophores, PATAI'S Chemistry of Functional Groups, 2010.

[18] J.B. Neilands, A crystalline organo-iron pigment from a rust fungus (Ustilago sphaerogena), J. Am. Chem. Soc. 74 (1952) 4846, doi:10.1021/ja01139a033

[19] C.W. Hesseltine, C. Pidacks, A.R. Whitehill, N. Bohonos, B.L. Hutchings, J.H. William, Coprogen, a new growth factor for Coprophilic Fungi, Communications to the editor 74 (1952) 1362, doi:10.1021/ja01125a525.

[20] T. Emery, J.B. Neilands, Contribution to the structure of the ferrichrome compounds: characterization of the acyl moieties of the hydroxamate functions, J. Am. Chem. Soc. 82 (1960) 3658-3662, doi:10.1021/ja01499a047.

[21] H. Bickel, G.E. Hall, W. Keller-Schierlein, V. Prelog, E. Vischer, A. Wettstein, 261. Stoffwechselprodukte von Actinomyceten uber die Konstitution von
Ferrioxamin B 27. Mitteilung, Helv. Chim. Acta XLIII (1960) 2129-2138, doi:10.1002/hlca.19600430732.

[22] H. Heli, S. Mirtorabi, K. Karimian, Advances in iron chelation: an update, Expert Opin. Ther. Pat. 21 (2011) 819-856, doi:10.1517/ 13543776.2011.569493.

[23] D.M. Reynolds, A. Schatz, S. Waksman, Grisein, a new antibiotic produced by a strain of Streptomyces griseus, Proc. Soc. Exp. Biol. Med. 64 (1947) 50-54, doi:10.3181/00379727-64-15695.

[24] G. Benz, L. Schroder, J. Kurz, C. Wiinsche, W. Karl, G. Steffens, J. Pfitzner, D. Schmidt, Constitution of the deferriform of the albomycins $\delta 1, \delta 2$ and $\varepsilon$, Angew Chem. Int. Ed. Engl. 21 (1982) 527-528, doi:10.1002/anie.198205271.

[25] J.M. Roosenberg II, Y. Lin, Y. Lu, M.J. Miller, Studies and syntheses of siderophores, microbial iron chelators, and analogs as potential drug delivery agents, Curr. Med. Chem. 7 (2000) 159-197, doi:10.2174/0929867003375353.

[26] E. Mawji, M. Gledhill, J.A. Milton, G.A. Tarran, S. Ussher, A. Thompson, G.A. Wolff, P.J. Worsfold, E.P. Achterberg, Hydroxamate siderophores: occurrence and importance in the Atlantic Ocean, Environ. Sci. Technol. 42 (2008) 8675-8680, doi:10.1021/es801884r.

[27] A. Butler, R.M. Theisen, Iron(III)-siderophore coordination chemistry: reactivity of marine siderophores, Coord. Chem. Rev. 254 (2010) 288-296, doi:10.1016/ j.ccr.2009.09.010.

28] J.S. Martinez, J.N. Carter-Franklin, E.L. Mann, J.D. Martin, M.G. Haygood, A. Butler, Structure and membrane affinity of a suite of amphiphilic siderophores produced by a marine bacterium, Proc. Natl. Acad. Sci. 100 (2003) 3754-3759, doi:10.1073/pnas.0637444100.

[29] J.M. Vraspir, P.D. Holt, A. Butler, Identification of new members within suites of amphiphilic marine siderophores, Biometals 24 (2011) 85-92, doi:10.1007/ s10534-010-9378-1.

[30] J.S. Martinez, G.P. Zhang, P.D. Holt, H.T. Jung, C.J. Carrano, M.G. Haygood, A. Butler, Self-assembling amphiphilic siderophores from marine bacteria, Science 287 (2000) 1245-1247, doi:10.1126/science.287.5456.1245.

[31] J.S. Martinez, A. Butler, Marine amphiphilic siderophores: marinobactin structure, uptake, and microbial partitioning, J. Inorg. Biochem. 101 (2007) 1692-1698, doi:10.1016/j.jinorgbio.2007.07.007.

[32] J.M. Gauglitz, A. Butler, Amino acid variability in the peptide composition of suite of amphiphilic peptide siderophores from an open ocean Vibrio species, J. Biol. Inorg. Chem. 18 (2013) 489-497, doi:10.1007/s00775-013-0995-3.

[33] S. Lautru, R.J. Deeth, L.M. Bailey, G.L. Challis, Discovery of a new peptide natural product by Streptomyces coelicolor genome mining, Nat. Chem. Biol. 1 (2005) 265-269, doi:10.1038/nchembio731.

[34] I. Nakamura, S. Yoshimura, T. Masaki, S. Takase, K. Ohsumi, M. Hashimoto, S. Furukawa, A. Fujie, ASP2397: a novel antifungal agent produced by Acremonium persicinum MF-347833, J. Antibiot. 70 (2017) 45-51, doi:10.1038/ ja.2016.107.

[35] M. Luo, R. Zang, X. Wang, Z. Chen, X. Song, J. Ju, H. Huang, Natural hydroxamate-containing siderophore acremonpeptides A-D and an aluminum complex of acremonpeptide D from the marine-derived Acremonium persicinum SCSIO 115, J. Nat. Prod. 82 (2019) 2594-2600, doi:10.1021/ acs.jnatprod.9b00545.

[36] K.-F. Mo, Z. Dai, D.S. Wunschel, Production and characterization of desmalonichrome relative binding affinity for uranyl ions in relation to other siderophores, J. Nat. Prod. 79 (2016) 1492-1499, doi:10.1021/ acs.jnatprod.5b00933.

[37] S. Kodani, H. Komaki, M. Suzuki, F. Kobayakawa, H. Hemmi, Structure determination of a siderophore peucechelin from Streptomyces peucetius, Biometals 28 (2015) 791-801, doi:10.1007/s10534-015-9866-4.

[38] T. Heine, M. Mehnert, R. Schwabe, D. Tischler, Thermochelin, a hydroxamate siderophore fromThermocrispum agreste DSM 44070, Solid State Phenom. 262 (2017) 501-504, doi:10.4028/www.scientific.net/SSP.262.501.

[39] L. Robbel, T.A. Knappe, U. Linne, X. Xie, M.A. Marahiel, Erythrochelin--a hydroxamate-type siderophore predicted from the genome of Saccharopolyspora erythraea, FEBS J. 277 (2010) 663-676, doi:10.1111/ j.1742-4658.2009.07512.x.

[40] S.B. Krasnoff, I. Keresztes, B.G.G. Donzelli, D.M. Gibson, Metachelins, mannosylated and N-oxidized coprogen-type siderophores from Metarhizium robertsii, J. Nat. Prod. 77 (2014) 1685-1692, doi:10.1021/np500300s.

[41] S.B. Krasnoff, K.J. Howe, M.L. Heck, B.G.G. Donzelli, Siderophores from the entomopathogenic fungus Beauveria bassiana, J. Nat. Prod. 83 (2020) 296-304, doi:10.1021/acs.jnatprod.9b00698.

[42] P. Kalansuriya, M. Quezada, B.P. Espósito, R.J. Capon, Talarazines A-E: noncytotoxic iron(III) chelators from an Australian mud dauber wasp-associated fungus, talaromyces sp. (CMB-W045), J. Nat. Prod. 80 (2017) 609-615, doi:10.1021/acs.jnatprod.6b00889.

[43] O. Wu, R.W. Deering, G. Zhang, B. Wang, X. Li, J. Sun, J. Chen, H. Zhang, D.C Rowley, H. Wang, Albisporachelin, a new hydroxamate type siderophore from the deep ocean sediment-derived actinomycete amycolatopsisalbispora WP1(T), Mar. Drugs 16 (2018) 199, doi:10.3390/md16060199.

[44] S. Kodani, F. Kobayakawa, M. Hidaki, Isolation and structure determination of new siderophore tsukubachelin B from Streptomyces sp. TM-74, Nat. Prod. Res. 27 (2013) 775-781, doi:10.1080/14786419.2012.698412.

[45] S. Kodani, H. Komaki, M. Suzuki, H. Hemmi, M. Ohnishi-Kameyama, Isolation and structure determination of new siderophore albachelin from Amycolatopsis alba, Biometals 28 (2015) 381-389, doi:10.1007/s10534-015-9842-z.

[46] S. Kodani, J. Bicz, L. Song, R.J. Deeth, M. Ohnishi-Kameyama, M. Yoshida, K. Ochi, G.L. Challis, Structure and biosynthesis of scabichelin, a novel tris-hydroxamate siderophore produced by the plant pathogen Streptomyces scabies 87.22, Org. Biomol. Chem. 11 (2013) 4686-4694, doi:10.1039/ c3ob40536b.

[47] W. Wright, J. Little, F. Liu, R. Chakraborty, Isolation and structural identification of the trihydroxamate siderophore vicibactin and its degradative 
products from Rhizobium leguminosarum ATCC 14479 bv, trifolii, BioMetals 26 (2013) 271-283, doi:10.1007/s10534-013-9609-3.

[48] W. Wang, Z. Chi, G. Liu, M.A. Buzdar, Z. Chi, Q. Gu, Chemical and biological characterization of siderophore produced by the marine-derived Aureobasidium pullulans HN6.2 and its antibacterial activity, Biometals 22 (2009) 965, doi:10.1007/s10534-009-9248-x.

[49] K. Haselwandter, V. Passler, S. Reiter, D.G. Schmid, G. Nicholson, P. Hentschel, K. Albert, G. Winkelmann, Basidiochrome - a novel siderophore of the orchidaceous mycorrhizal fungi ceratobasidium and rhizoctonia spp, Biometals 19 (2006) 335-343, doi:10.1007/s10534-006-6986-x.

[50] S. Kokubo, K. Suenaga, C. Shinohara, T. Tsuji, D. Uemura, Structures of amamistatins A and B, novel growth inhibitors of human tumor cell lines from an actinomycete, Tetrahedron Lett. 40 (1999) 1945-1948, doi:10.1016/ S0040-4039(99)00050-7.

[51] S. Kokubo, K. Suenaga, C. Shinohara, T. Tsujib, D. Uemura, Structures of amamistatins A and B, novel growth inhibitors of human tumor cell lines from Nocardia asteroides, Tetrahedron 56 (2000) 6435-6440, doi:10.1016/ S0040-4020(00)00591-3.

[52] M. Tsuda, M. Yamakawa, S. Oka, Y. Tanaka, Y. Hoshino, Y. Mikami, A. Sato, H. Fujiwara, Y. Ohizumi, J. Kobayashi, Brasilibactin A, a cytotoxic compound from actinomycete Nocardia brasiliensis, J. Nat. Prod. 68 (2005) 462-464, doi:10.1021/np0496385.

[53] Y. Ikeda, H. Nonaka, T. Furumai, H. Onaka, Y. Igarashi, Nocardimicins A, B, C $\mathrm{D}, \mathrm{E}$, and F, siderophores with muscarinic M3 receptor inhibiting activity from nocardia sp. TP-a0674, J. Nat. Prod. 68 (2005) 1061-1065, doi:10.1021/ np050091j.

[54] Y. Ikeda, T. Furumai, Y. Igarashi, Nocardimicins G, H and I, siderophores with muscarinic M3 receptor binding inhibitory activity from Nocardia nova JCM 6044, J. Antibiot. 58 (2005) 566-572, doi:10.1038/ja.2005.77.

[55] K. Schneider, I. Rose, S. Vikineswary, A.L. Jones, M. Goodfellow, G. Nicholson, W. Beil, R.D. Süssmuth, H.-P. Fiedler, Nocardichelins A and B, siderophores from nocardia strain acta 3026, J. Nat. Prod. 70 (2007) 932-935, doi:10.1021/ np060612i.

[56] J.-H. Jang, K. Kanoh, K. Adachi, S. Matsuda, Y. Shizuri, Tenacibactins A-D, hydroxamate siderophores from a marine-derived bacterium, tenacibaculum $\mathrm{sp}$. A4K-17, J. Nat. Prod. 70 (2007) 563-566, doi:10.1021/np060502b.

[57] F. Maglangit, M.H. Tong, M. Jaspars, K. Kyeremeh, H. Deng, Legonoxamines A-B, two new hydroxamate siderophores from the soil bacterium, Streptomyces sp. MA37, Tetrahedron Lett. 60 (2019) 75-79, doi:10.1016/ j.tetlet.2018.11.063.

[58] G. Winkelmann, D.G. Schmid, G. Nicholson, G. Jung, D.J. Colquhoun, Bisucaberin - a dihydroxamate siderophore isolated from Vibrio salmonicida, an important pathogen of farmed Atlantic salmon (Salmo salar), Biometals 15 (2002) 153-160, doi:10.1023/A:1015206419613.

[59] T. Böttcher, J. Clardy, A chimeric siderophore halts swarming Vibrio, Angew. Chem. Int. Ed. 53 (2014) 3510-3513, doi:10.1002/anie.201310729.

[60] M. Bosello, L. Robbel, U. Linne, X. Xie, M.A. Marahiel, Biosynthesis of the siderophore rhodochelin requires the coordinated expression of three independent gene clusters in Rhodococcus jostii RHA1, J. Am. Chem. Soc. 133 (2011) 4587-4595, doi:10.1021/ja1109453.

[61] H.K. Zane, A. Butler, Isolation, structure elucidation, and iron-binding properties of lystabactins, siderophores isolated from a marine pseudoalteromonas sp, J. Nat. Prod. 76 (2013) 648-654, doi:10.1021/ np3008655.

[62] S. Dhungana, R. Michalczyk, H. Boukhalfa, J.G. Lack, A.T. Koppisch, J.M. Fairlee, M.T. Johnson, C.E. Ruggiero, S.G. John, M.M. Cox, C.C. Browder, J.H. Forsythe, L.A. Vanderberg, M.P. Neu, L.E. Hersman, Purification and characterization of rhodobactin: a mixed ligand siderophore from Rhodococcus rhodochrous strain OFS, Biometals 20 (2007) 853-867, doi:10.1007/ s10534-006-9079-y.

[63] M. Bosello, M. Zeyadi, F.I. Kraas, U. Linne, X. Xie, M.A. Marahiel, Structural characterization of the heterobactin siderophores from Rhodococcus erythropolis PR4 and elucidation of their biosynthetic machinery, J. Nat. Prod. 76 (2013) 2282-2290, doi:10.1021/np4006579.

[64] A. Mukai, H. Komaki, M. Takagi, K. Shin-ya, Novel siderophore, JBIR-16, isolated from Nocardia tenerifensis NBRC 101015, J. Antibiot. 62 (2009) 601-603, doi:10.1038/ja.2009.84.

[65] E.J. Dimise, P.F. Widboom, S.D. Bruner, Structure elucidation and biosynthesis of fuscachelins, peptide siderophores from the moderate thermophile Thermobifida fusca, Proc. Natl. Acad. Sci. 105 (2008) 15311-15316, doi:10.1073/pnas.0805451105.

[66] M. Sandy, A. Han, J. Blunt, M. Munro, M. Haygood, A. Butler, Vanchrobactin and anguibactin siderophores produced by Vibrio sp. DS40M4, J. Nat. Prod. 73 (2010) 1038-1043, doi:10.1021/np900750g.

[67] A. Proschak, P. Lubuta, P. Grun, F. Lohr, G. Wilharm, V. De Berardinis, H.B. Bode, Structure and biosynthesis of fimsbactins A-F, siderophores from Acinetobacter baumannii and Acinetobacter baylyi, ChemBioChem 14 (2013) 633-638, doi:10.1002/cbic.201200764.

[68] C. Kurth, S. Schieferdecker, K. Athanasopoulou, I. Seccareccia, M. Nett, Variochelins, lipopeptide siderophores from Variovorax boronicumulans discovered by genome mining, J. Nat. Prod. 79 (2016) 865-872, doi:10.1021/ acs.jnatprod.5b00932.

[69] A.W. Robertson, N.G. McCarville, L.W. MacIntyre, H. Correa, B. Haltli, D.H. Marchbank, R.G. Kerr, Isolation of imaqobactin, an amphiphilic siderophore from the arctic marine bacterium variovorax species RKJM285, J. Nat. Prod. 81 (2018) 858-865, doi:10.1021/acs.jnatprod.7b00943.

[70] C.W. Johnston, M.A. Skinnider, M.A. Wyatt, X. Li, M.R.M. Ranieri, L. Yang, D.L. Zechel, B. Ma, N.A. Magarvey, An automated Genomes-to-Natural Products platform (GNP) for the discovery of modular natural products, Nat. Commun. 6 (2015) 8421, doi:10.1038/ncomms9421.
[71] V.V. Homann, M. Sandy, J.A. Tincu, A.S. Templeton, B.M. Tebo, A. Butler, Loihichelins A-F, a suite of amphiphilic siderophores produced by the marine bacterium H. LOB-5, J. Nat. Prod. 72 (2009) 884-888, doi:10.1021/ np800640h.

[72] C.D. Hardy, A. Butler, Ambiguity of NRPS structure predictions: four bidentate chelating groups in the siderophore pacifibactin, J. Nat. Prod. 82 (2019) 990-997, doi:10.1021/acs.jnatprod.8b01073.

[73] F. Rosconi, D. Davyt, V. Martinez, M. Martinez, J.A. Abin-Carriquiry, H. Zane, A. Butler, E.M. de Souza, E. Fabiano, Identification and structural characterization of serobactins, a suite of lipopeptide siderophores produced by the grass endophyte Herbaspirillum seropedicae, Environ. Microbiol. 15 (2013) 916-927, doi:10.1111/1462-2920.12075.

[74] M.F. Kreutzer, H. Kage, M. Nett, Structure and biosynthetic assembly of cupriachelin, a photoreactive siderophore from the bioplastic producer Cupriavidus necator H16, J. Am. Chem. Soc. 134 (2012) 5415-5422, doi:10.1021/ja300620z.

[75] J.R. Carmichael, H. Zhou, A. Butler, A suite of asymmetric citrate siderophores isolated from a marine Shewanella species, J. Inorg. Biochem. 198 (2019) 110736, doi:10.1016/j.jinorgbio.2019.110736.

[76] J.D. Martin, Y. Ito, V.V. Homann, M.G. Haygood, A. Butler, Structure and membrane affinity of new amphiphilic siderophores produced by Ochrobactrum sp. SP18, J. Biol. Inorg. Chem. 11 (2006) 633-641, doi:10.1007/ s00775-006-0112-y.

[77] Y. Ito, A. Butler, Structure of synechobactins, new siderophores of the marine cyanobacterium Synechococcus sp. PCC 7002, Limnol. Oceanogr. 50 (2005) 1918-1923, doi:10.4319/lo.2005.50.6.1918.

[78] E.P. Storey, R. Boghozian, J.L. Little, D.W. Lowman, R. Chakraborty, Characterization of 'Schizokinen'; a dihydroxamate-type siderophore produced by Rhizobium leguminosarum IARI 917, Biometals 19 (2006) 637-649, doi:10.1007/s10534-006-9001-7.

[79] W.F. Penwell, N. DeGrace, S. Tentarelli, L. Gauthier, C.M. Gilbert, B.A. Arivett, A.A. Miller, T.F. Durand-Reville, C. Joubran, L.A. Actis, Discovery and characterization of new hydroxamate siderophores, baumannoferrin A and B, produced by Acinetobacter baumannii, ChemBioChem 16 (2015) 1896-1904, doi:10.1002/cbic.201500147.

[80] S. Hoshino, M. Ozeki, T. Awakawa, H. Morita, H. Onaka, I. Abe, Catenulobactins A and B, heterocyclic peptides from culturing catenuloplanes sp. with a mycolic acid-containing bacterium, J. Nat. Prod. 81 (2018) 2106-2110, doi:10.1021/acs.jnatprod.8b00261.

[81] T.W. Giessen, K.B. Franke, T.A. Knappe, F.I. Kraas, M. Bosello, X. Xie, U. Linne, M.A. Marahiel, Isolation, structure elucidation, and biosynthesis of an unusual hydroxamic acid ester-containing siderophore from Actinosynnema mirum, J. Nat. Prod. 75 (2012) 905-914, doi:10.1021/np300046k.

[82] R. Hermenau, K. Ishida, S. Gama, B. Hoffmann, M. Pfeifer-Leeg, W. Plass, J.F. Mohr, T. Wichard, H.-P. Saluz, C. Hertweck, Gramibactin is a bacterial siderophore with a diazeniumdiolate ligand system, Nat. Chem. Biol. 14 (2018) 841-843, doi:10.1038/s41589-018-0101-9.

[83] A. Pesic, B. Steinhaus, S. Kemper, J. Nachtigall, H.J. Kutzner, G. Höfle, R.D Süssmuth, Isolation and structure elucidation of the nucleoside antibiotic strepturidin from Streptomyces albus DSM 40763, J. Antibiot. 67 (2014) 471-477, doi:10.1038/ja.2014.16.

[84] B. Winterberg, S. Uhlmann, U. Linne, F. Lessing, M.A. Marahiel, H. Eichhorn, R. Kahmann, J. Schirawski, Elucidation of the complete ferrichrome A biosynthetic pathway in Ustilago maydis, Mol. Microbiol. 75 (2010) 1260-1271, doi:10.1111/j.1365-2958.2010.07048.x.

[85] E.K. Dolence, C.-E. Lin, M.J. Miller, Synthesis and siderophore activity of albomycin-like peptides derived from N5-acety1-N5-hydroxy-L-ornithine, J. Med. Chem. 34 (1991) 956-968, doi:10.1021/jm00107a013.

[86] A. Ganeshpurkar, D. Kumar, S.K. Singh, Strategies for the synthesis of hydroxamic acids, Curr. Org. Synth. 15 (2018) 154-165, doi:10.2174/ 1570179414666170614123508.

[87] Y. Lin, M.J. Miller, Practical synthesis of hydroxamate-derived siderophore components by an indirect oxidation method and syntheses of a DIG-siderophore conjugate and a biotin-siderophore conjugate, J. Org. Chem. 64 (1999) 7451-7458, doi:10.1021/jo990769y.

[88] R. Mashiach, M.M. Meijler, Total synthesis of pyoverdin D, Org. Lett. 15 (2013) 1702-1705, doi:10.1021/ol400490s.

[89] Z. Lin, X. Xu, S. Zhao, X. Yang, J. Guo, Q. Zhang, C. Jing, S. Chen, Y. He, Total synthesis and antimicrobial evaluation of natural albomycins against clinical pathogens, Nat. Commun. 9 (2018) 3445, doi:10.1038/s41467-018-05821-1.

[90] Y. Isowa, M. Ohmori, H. Kurita, Total synthesis of ferrichrome, Bull. Chem. Soc. Jpn. 47 (1974) 215-220, doi:10.1246/bcsj.47.215

[91] W. Keller - Schierlein, B. Maurer, 67. Metabolic products of microorganisms Synthesis of ferrichrome; Part 2, Helv. Chim. Acta 52 (1969) 603-610, doi:10.1002/hlca.19690520307.

[92] P. Cherkupally, S. Ramesh, T. Govender, H.G. Kruger, B.G. de la Torre, F. Albericio, An efficient solid-phase strategy for total synthesis of naturally occurring amphiphilic marine siderophores: amphibactin- $\mathrm{T}$ and moanachelin ala-B, Org. Biomol. Chem. 13 (2015) 4760-4768, doi:10.1039/c5ob00100e.

[93] R.J. Bergeron, J.J. Pegram, An efficient total synthesis of desferrioxamine B, J. Org. Chem. 53 (1988) 555-558, doi:10.1021/jo00249a001.

[94] R. Bergemn, J. McManis, The total synthesis of Bisucaberin, Tetrahedron 45 (1989) 4939-4944, doi:10.1016/S0040-4020(01)81074-7

[95] R. Bergeron, J. McManis, P. Perumal, S. Algee, The total synthesis of alcaligin, J. Org. Chem. 56 (1991) 5560-5563, doi:10.1021/jo00019a017.

[96] S. Zhang, L.M. De Leon Rodriguez, R. Huang, I.K.H. Leung, P.W.R. Harris, M.A Brimble, Total synthesis of the proposed structure of talarolide A, Org. Biomol. Chem. 16 (2018) 5286-5293, doi:10.1039/c8ob01230j. 
[97] Y. Ye, M. Liu, J. Kao, G.R. Marshall, Peptide-bond modification for metal coordination: peptides containing two hydroxamate groups, Biopolymers 71 (2003) 489-515, doi:10.1002/bip.10471.

[98] Y. Ye, M. Liu, J.L. Kao, G.R. Marshall, Novel trihydroxamate-containing peptides: design, synthesis, and metal coordination, Biopolymers 84 (2006) 472-489, doi:10.1002/bip.20532.

[99] M.P. Sarnowski, J. Del Valle, N-Hydroxy peptides: solid-phase synthesis and $\beta$-sheet propensity, Org. Biomol. Chem. (2020) 3690-3696, doi:10.1039/ d0ob00664e.

[100] R. Kachadourian, S. Chuilon, C. Mérienne, G. Kunesch, A. Deroussent, A new total synthesis of ferrioxamine $\mathrm{E}$ through metal-templated cyclic trimerization, Supramol. Chem. 8 (1997) 301-308, doi:10.1080/10610279708034949.

[101] J.M. Roosenberg, M.J. Miller, Total synthesis of the siderophore danoxamine, J. Org. Chem. 65 (2000) 4833-4838, doi:10.1021/jo000050m.

[102] A.L. Crumbliss, J.M. Harrington, Iron Sequestration by Small Molecules: Thermodynamic and Kinetic Studies of Natural Siderophores and Synthetic Model Compounds, 2009, pp. 179-250.

[103] R.C. Scarrow, D.J. Ecker, C. Ng, S. Liu, K.N. Raymond, Iron(III) coordination chemistry of linear dihydroxyserine compounds derived from enterobactin, Inorg. Chem. 30 (1991) 900-906, doi:10.1021/ic00005a007.

[104] G. Anderegg, F.L. Eplattenier, G. Schwarzenbach, 156. Hydroxamatkomplexe (III). Eisen(III)-Austausch zwischen Sideraminen und Komplexonen Diskussion der Bildungskonstanten der Hydroxamatkomplexe, Helv. Chim. Acta 156 (1963) 1409-1422, doi:10.1002/hlca.19630460436.

[105] S. Dhungana, S. Heggemann, P. Gebhardt, U. Mollmann, A.L. Crumbliss, Fe(III) coordination properties of a new saccharide-based exocyclic trihydroxamate analogue of ferrichrome, Inorg. Chem. 42 (2003) 42-50, doi:10.1021/ ic025647u.

[106] S. Dhungana, J.M. Harrington, P. Gebhardt, U. Mollmann, A.L. Crumbliss, Iron chelation equilibria, redox, and siderophore activity of a saccharide platform ferrichrome analogue, Inorg. Chem. 46 (2007) 8362-8371, doi:10.1021/ ic0701581.

[107] J.M. Harrington, G. Winkelmann, K. Haselwandter, A.L. Crumbliss, Fe(III)-complexes of the tripodal trishydroxamate siderophore basidiochrome: potential biological implications, J. Inorg. Biochem. 105 (2011) 1670-1674, doi:10.1016/j.jinorgbio.2011.08.010.

[108] G. Zhang, S.A. Amin, F.C. Kupper, P.D. Holt, C.J. Carrano, A. Butler, Ferric stability constants of representative marine siderophores: marinobactins, aquachelins, and petrobactin, Inorg. Chem. 48 (2009) 11466-11473, doi:10.1021/ic901739m.

[109] S.S. Ali, N.N. Vidhale, Bacterial siderophore and their application: a review, Int. J. Curr. Microbial. Appl. Sci. 2 (2013) 303-312.

[110] M. Petrik, C. Zhai, H. Haas, C. Decristoforo, Siderophores for molecular imaging applications, Clin. Transl. Imag. 5 (2017) 15-27, doi:10.1007/ s40336-016-0211-x.

[111] X. Hu, J. Zhu, S. Srivathsan, D. Pei, Peptidyl hydroxamic acids as methionine aminopeptidase inhibitors, Bioorg. Med. Chem. Lett 14 (2004) 77-79, doi:10.1016/j.bmcl.2003.10.031.

[112] T.A. Wencewicz, M.J. Miller, Sideromycins as pathogen-targeted antibiotics, Antibacterials, 2017, pp. 151-183.

[113] M. Taouai, K. Chakroun, R. Sommer, G. Michaud, D. Giacalone, M.A. Ben Maaouia, A. Vallin-Butruille, D. Mathiron, R. Abidi, T. Darbre, P.J. Cragg, C. Mullie, J.L. Reymond, G.A. O'Toole, M. Benazza, Glycocluster tetrahydroxamic acids exhibiting unprecedented inhibition of Pseudomonas aeruginosa biofilms, J. Med. Chem. 62 (2019) 7722-7738, doi:10.1021/acs.jmedchem.9b00481.

[114] M. Hannauer, Y. Barda, G.L. Mislin, A. Shanzer, I.J. Schalk, The ferrichrome uptake pathway in Pseudomonas aeruginosa involves an iron release mechanism with acylation of the siderophore and recycling of the modified desferrichrome, J. Bacteriol. 192 (2010) 1212-1220, doi:10.1128/JB.01539-09.

[115] R. Nudelman, O. Ardon, Y. Hadar, Y. Chen, J. Libman, A. Shanzer, Modular fluorescent-labeled siderophore analogues, J. Med. Chem. 41 (1998) 1671-1678, doi:10.1021/jm970581b.

[116] I. Dayan, J. Libman, Y. Agi, A. Shanzer, Chiral siderophore analogs: ferrichrome, Inorg. Chem. 32 (1993) 1467-1475, doi:10.1021/ic00060a024.

[117] F.A. Kuehl, M.N. Bishop, L. Chaiet, K. Folkers, Isolation and some chemical properties of grisein, J. Am. Chem. Soc. 73 (1951) 1770-1773, doi:10.1021/ ja01148a099.

[118] G.F. Gause, Recent studies on Albomycin, a new antibiotic, Br. Med. J. 2 (1955) 1177-1179, doi:10.1136/bmj.2.4949.1177.

[119] E.O. Stapley, R.E. Ormond, Similarity of albomycin and grisein, Science 125 (1957) 587-589, doi:10.1126/science.125.3248.587.

[120] A. Hartmann, H. Fiedler, V. Braun, Uptake and conversion of the antibiotic albomycin Escherichia coli K-12, Eur. J. Biochem. 99 (1979) 517-524, doi:10.1111/j.1432-1033.1979.tb13283.x.

[121] L. Vertesy, W. Aretz, H.-W. Fehlhaber, H. Kogler, 3. Salmycin A-D, Antibiotika aus Streptomyces violaceus, DSM 8286, mit Siderophor-Aminoglycosid-Struktur, Helv. Chim. Acta 78 (1995) 46-60, doi:10.1002/hlca.19950780105.

[122] A.L. Stefanska, M. Fulston, C. Houge-Frydrych, J. Jones, S.R. Warr, A potent seryl tRNA synthetase inhibitor SB-217452 isolated from a Streptomyces species, J. Antibiot. 53 (2000) 1346-1353, doi:10.7164/antibiotics.53.1346.

[123] P. Ding, C.E. Schous, M.J. Miller, Design and synthesis of a novel protected mixed ligand siderophore, Tetrahedron Lett. 49 (2008) 2306-2310, doi:10.1016/j.tetlet.2008.02.007.

[124] Cefiderocol approval letterhttps://www.accessdata.fda.gov/drugsatfda_docs/ nda/2019/2094450rig1s000ltr.pdf22 August 2020

[125] Y. Saisho, T. Katsube, S. White, H. Fukase, J. Shimada, Pharmacokinetics, safety, and tolerability of cefiderocol, a novel siderophore cephalosporin for gram-negative bacteria, in healthy subjects, Antimicrob. Agents Chemother. (2018) 62, doi:10.1128/AAC.02163-17.
[126] E.K. Dolence, A.A. Minnick, M.J. Miller,

N5-Acetyl-N5-hydroxy-L-ornithine-Derived siderophore-carbacephalosporin \&lactam conjugates: iron transport mediated drug delivery, J. Med. Chem. 33 (1990) 464-479, doi:10.1021/jm00164a001.

[127] A. Brochu, N. Brochu, T.I. Nicas, T.R. Parr Jr., A.A. Minnick Jr., E.K. Dolence, J.A. McKee, M.J. Miller, M.C. Lavoie, F. Malouin, Modes of action and inhibitory activities of new siderophore-beta-lactam conjugates that use specific iron uptake pathways for entry into bacteria, Antimicrob. Agents Chemother. 36 (1992) 2166-2175, doi:10.1128/aac.36.10.2166.

[128] E.K. Dolence, A.A. Minnick, C.-E. Lin, M.J. Miller, Synthesis and siderophore and antibacterial activity of N5-acetyl-N5-hydroxy-L-ornithine-Derived siderophore-?-lactam conjugates: iron-transport-mediated drug delivery, J. Med. Chem. 34 (1991) 968-978, doi:10.1021/jm00107a014.

[129] A. Pandey, C. Savino, S.H. Ahn, Z. Yang, S.G. Van Lanen, E. Boros, Theranostic gallium siderophore ciprofloxacin conjugate with broad spectrum antibiotic potency, J. Med. Chem. 62 (2019) 9947-9960, doi:10.1021/ acs.jmedchem.9b01388.

[130] Y.-M. Lin, P. Helquist, M.J. Miller, Synthesis and biological evaluation of a siderophore-virginiamycin conjugate, Synthesis S1 (1999) 1510-1514, doi:10.1055/s-1999-3655.

[131] M. Ghosh, M.J. Miller, Iron transport-mediated drug delivery: synthesis and biological evaluation of cyanuric acid-based siderophore analogs and ?-Lactam conjugates, J. Org. Chem. 59 (1994) 1020-1026, doi:10.1021/jo00084a018.

[132] C. Ji, M.J. Miller, Chemical syntheses and in vitro antibacterial activity of two desferrioxamine B-ciprofloxacin conjugates with potential esterase and phosphatase triggered drug release linkers, Bioorg. Med. Chem. 20 (2012) 3828-3836, doi:10.1016/j.bmc.2012.04.034.

[133] R.E. Juarez-Hernandez, P.A. Miller, M.J. Miller, Syntheses of siderophore-drug conjugates using a convergent thiol-maleimide system, ACS Med. Chem. Lett. 3 (2012) 799-803, doi:10.1021/ml300150y.

[134] T.A. Wencewicz, T.E. Long, U. Mollmann, M.J. Miller, Trihydroxamate siderophore-fluoroquinolone conjugates are selective sideromycin antibiotics that target Staphylococcus aureus, Bioconjugate Chem. 24 (2013) 473-486, doi:10.1021/bc300610f.

[135] T.A. Wencewicz, U. Mollmann, T.E. Long, M.J. Miller, Is drug release necessary for antimicrobial activity of siderophore-drug conjugates? Syntheses and biological studies of the naturally occurring salmycin "Trojan Horse" antibiotics and synthetic desferridanoxamine-antibiotic conjugates, Biometals 22 (2009) 633-648, doi:10.1007/s10534-009-9218-3.

[136] S. Wittmann, M. Schnabelrauch, I. Scherlitz-Hofmann, U. Mõllmann, D. Ankel-Fuchs, L. Heinisch, New synthetic siderophores and their ß-lactam conjugates based on diamino acids and dipeptides, Bioorg. Med. Chem. 10 (2002) 1695-1670, doi:10.1016/s0968-0896(02)00044-5.

[137] A. Ghosh, M. Ghosh, C. Niu, F. Malouin, U. Moellmann, M.J. Miller, Iron transport-mediated drug delivery using mixed-ligand siderophore- $\beta$-Lactam conjugates, Chem. Biol. 3 (1996) 1011-1019, doi:10.1016/ S1074-5521(96)90167-2.

[138] T.A. Wencewicz, M.J. Miller, Biscatecholate-monohydroxamate mixed ligand siderophore-carbacephalosporin conjugates are selective sideromycin antibiotics that target Acinetobacter baumannii, J. Med. Chem. 56 (2013) 4044-4052, doi:10.1021/jm400265k.

[139] M. Ghosh, P.A. Miller, U. Mollmann, W.D. Claypool, V.A. Schroeder, W.R. Wolter, M. Suckow, H. Yu, S. Li, W. Huang, J. Zajicek, M.J. Miller, Targeted antibiotic delivery: selective siderophore conjugation with daptomycin confers potent activity against multidrug resistant acinetobacter baumannii both in vitro and in vivo, J. Med. Chem. 60 (2017) 4577-4583, doi:10.1021/ acs.jmedchem.7b00102.

[140] O. Kinzel, R. Tappe, I. Gerus, H. Budzikiewicz, The synthesis and antibacterial activity of two pyoverdin-ampicillin conjugates, entering Pseudomonas aeruginosa via the pyoverdin-mediated iron uptake pathway, J. Antibiot. 51 (1998) 499-507, doi:10.7164/antibiotics.51.499.

[141] O. Kinzel, H. Budzikiewicz, Synthesis and biological evaluation of a pyoverdin-blactam conjugate: a new type of arginine-specific crosslinking in aqueous solution, J. Pept. Res. 53 (1999) 618-625, doi:10.1034/ j.1399-3011.1999.00053.x.

[142] A.P. Murray, M.J. Miller, The preparation of a fully differentiated "multiwarhead" siderophore precursor, J. Org. Chem. 68 (2003) 191-194, doi:10.1021/jo026391c.

[143] S.H. Ahn, D. Thach, B.A. Vaughn, V.M. Alford, A.N. Preston, S.T. Laughlin, E. Boros, Linear desferrichrome-linked silicon-rhodamine antibody conjugate enables targeted multimodal imaging of HER2 in vitro and in vivo, Mol. Pharm. 16 (2019) 1412-1420, doi:10.1021/acs.molpharmaceut.8b01278.

[144] J.Y. Wu, P. Srinivas, J.M. Pogue, Cefiderocol: a novel agent for the management of multidrug-resistant gram-negative organisms, Infect. Dis. Ther. 9 (2020) 17-40, doi:10.1007/s40121-020-00286-6.

[145] T. Sato, K. Yamawaki, Cefiderocol: discovery, chemistry, and in vivo profiles of a novel siderophore cephalosporin, Clin. Infect. Dis. 69 (2019) S538-S543, doi:10.1093/cid/ciz826.

[146] R.M. El-Lababidi, J.G. Rizk, Cefiderocol: a siderophore cephalosporin, Ann. Pharmacother. (2020) 1060028020929988, doi:10.1177/1060028020929988.

[147] Cefiderocol drug labelhttps://www.accessdata.fda.gov/drugsatfda_docs/nda/ 2019/209445Orig1s000Lbl.pdf22 August 2020 